\title{
ESTUDIO DE ALMIDONES EN QUEROS DE MADERA DEL NORTE DE \\ Chile Relacionados CON El CONSUMO DE CHICHA DURANTE EL HorizOnTE InCA
}

\author{
Bernardo Arriaza' ${ }^{1}$ Juan Pablo Ogalde 2 , Juan Chacama ${ }^{3}$, Vivien Standen³ Luis Huamán ${ }^{4}$ \\ y Fiorella Villanueva ${ }^{4}$
}

\section{* Introducción}

\begin{abstract}
Resumen
Se presentan los resultados de los análisis realizados a micro-restos botánicos (granos de almidón) extraídos de las paredes internas y fondo de 17 queros de madera del extremo norte de Chile. Estos queros representan cinco tipos diferentes de vasijas y están relacionados con el consumo de chicha durante el período Intermedio Tardío y Horizonte Inca. Los granos de almidón fueron separados por gravimetría y observados con montaje directo. Quince de estos queros dieron positivos para la presencia de granos de almidón crudo de maíz (Zea mays), algunos de los cuales muestran signos de fermentación. Además de maíz se encontraron granos de almidón de frijol (Phaseolus vulgaris), pallar (Phaseolus lunatus) y yuca (Manihot esculenta) entre otras especies. Se plantea que los aspectos

técnicos y contextuales en la producción de chicha de maíz local, no cocida, difieren de lo descrito en las crónicas para este período respecto de las áreas nucleares del Tawantinsuyo. Esta compleja evidencia encontrada en los queros de madera analizados incluyó el consumo de diversos tipos

de vegetales, probablemente procesados e incorporados en la forma de harinas. Se concluye que esto indicaría variantes regionales del protocolo de elaboración y consumo de chicha, posiblemente asociado a aspectos nutritivos y de ritualidad fúnebre local.
\end{abstract}

Palabras claves: fermentados - Valles Occidentales - libaciones rituales mortuorios - Arica.

\begin{abstract}
This paper presents the results of botanical analyses undertaken on micro-remains (starch grains) collected from the internal wall and base of five different types of queros of a total of 17 vessels. These queros are associated with chicha production during the Late Intermediate and Inca Horizon periods in northern Chile. The starch grains were separated by gravimetry and observed on microscope slides. Fifteen of these queros were positive for starch grains of corn (Zea mays) and some of these also contained evidence of fermented corn. In addition, we found starches of the common bean (Phaseolus vulgaris), lima bean (Phaseolus lunatus) and yucca (Manihot esculenta), among other species. These local findings differ from the contextual and technical aspects of chicha production described by the chroniclers for the nuclear area of Tawantinsuyo. Evidence found in the wooden queros and the different plant starches suggest grinding of these products and perhaps adding them as flour to the chicha. We conclude that this indicates regional variation in the protocols of production and consumption of chicha that were more likely related to dietary intake and local mortuary rites.
\end{abstract}

Key words: fermented drinks - Western Valleys - libations mortuary rites - Arica
El estudio de bebidas fermentadas (chichas) a partir de Zea mays (maíz) es importante en los Andes dadas sus múltiples funciones y beneficios como fuente de alimentación, elemento de colusión, evasión, socialización, política, estatus, hospitalidad y ritualidad (Cavero 1986; Dillehay 2003). Durante el Horizonte Inca (1450-1532 DC) o Tawantinsuyo, la chicha de maíz fue utilizada por el Estado de forma coercitiva y como instrumento de control social. Según Dillehay (2003: 360), para el Estado inca el consumo de chichas tenía tres funciones políticosociales muy importantes: a) integración y relaciones sociales, incluyendo la solidaridad, reciprocidad y desigualdad social, b) estatus institucionalizado a través de protocolos establecidos en el orden de beber, sexo, clase, etc., y c) retórica elitista de legitimización política, junto a la acción y materialidad especializada como vasijas exóticas y costosas.

Durante el período mencionado, la producción y consumo de la chicha seguía protocolos estrictos de libación, jerarquías, cantidades consumidas y estados de embriaguez permitidos (Randall 1993; Dillehay 2003). Estos aspectos han sido estudiados para el área nuclear, pero no han recibido el mismo énfasis en la periferia

Recibido: Mayo 2014. Aceptado: Febrero 2015

1 Instituto de Alta Investigación, Universidad de Tarapacá. Antofagasta 1520, Arica, CHILE. Email: barriazaarica@gmail.com

2 Departamento de Química, Facultad de Ciencias, Universidad de Tarapacá. General Velásquez 1775, Arica, CHILE. Email: jpabloogalde@yahoo.es

3 Departamento de Antropología, Facultad de Ciencias Sociales y Jurídicas, Universidad de Tarapacá. 18 de Septiembre 2222, Arica, CHILE.Email: vivien.standen@gmail.com y juanchacama@gmail.com

4 Laboratorio de Palinología y Paleobotánica de la Universidad Peruana Cayetano Heredia. Av. Honorio Delgado 430, Urbanización Ingeniería, S.M.P. Lima, PERU. Email: luis.huaman@upch.pe y fiorella. villanueva.r@upch.pe 
del Tawantinsuyo (p.e. valle de Azapa, norte de Chile), ya que como lo plantea Dillehay (2003), es importante centrarse en las relaciones de producción social local, versus el enfoque clásico centro-periferia. Así, a partir de la funebria local, se profundiza en el consumo de chichas, considerando su contexto general, la calidad de preservación de los materiales de libaciones y sus contenidos. De esta manera, como primer paso para debatir estas problemáticas en el ámbito local, se intenta responder algunas interrogantes claves como, qué tipos de fermentados se consumían, cuál era su calidad final, ingredientes, formas de preparación e instrumentos utilizados.

Para ello, se presentan los análisis de micro-restos arqueobotánicos de contenido sedimentario provenientes de diferentes tipos de vasos de madera del período Intermedio Tardío (1200-1450 DC) y del período Tardío u Horizonte Inca del extremo norte de Chile, utilizando colecciones depositadas en el Museo Arqueológico de la Universidad de Tarapacá San Miguel de Azapa de Arica (MASMA). Nuestro foco de análisis es el Horizonte Inca y el estudio propuesto es el consumo local de chicha de maíz en vasos de madera, lo cual necesita de una amplia contextualización preliminar, presentada a continuación para fundamentar nuestros supuestos básicos en la presentación e interpretación de los datos.

\section{Los queros en el mundo inca}

Los queros ${ }^{5}$ son recipientes en forma de vasos troncocónicos o hiperboloides, manufacturados en distintas materialidades, que fueron utilizados para la ingesta de líquidos, preferentemente fermentados de maíz, en gran parte del área andina prehispánica y colonial (Rowe 1961; Núñez 1963; Espoueys 1974; Ziółkowski 1979; Cummins 2004; Mulvany 2004; Martínez 2008; Lizárraga 2009; Horta 2013; Martínez et al. 2014). Durante el desarrollo del Tawantinsuyo los queros formaban parte importante de la ideología de legitimación sobre los orígenes dinásticos del Estado inca y en la dinámica material de su expansión territorial (Ziółkowski 1979; Dillehay 2003; Cummins 2004; Pease 2004). Varios cronistas consignan la presencia de estos vasos confeccionados en oro y plata, y en pares, denominados aquillas, en el mito de origen inca de los hermanos Ayar quienes salieron de la cueva Tampu T'oqo cercana a Pacaritambo en Cusco (Randall 1993; Cummins 2004). Al respecto, Santa Cruz Pacha- cuti (1993 [ca.1615]: 194) menciona que cuando Manco Capac (el primer inca) y sus hermanos salieron de Pacaritambo a conquistar nuevas tierras, llevaban consigo el tupa yauri de oro (cetro ceremonial con forma de hacha) y "dos aquillas de oro pequeños con que abía bevido el dicho Tunapa [Viracocha] se llamó tupa cusi" (Cummins 2004: 106) ${ }^{6}$. De esta manera, los aquillas de oro relacionados directamente con el Inca se llamaban tupa cusi.

Conviene señalar que a diferencia del tupa yauri, que en la mitología fue un cetro de madera regalado por Viracocha al padre de Manco Capac, que como buen augurio se convierte en oro cuando nace éste, los pares de tupa cusi habían sido traídos por Tunupa desde el Collasuyo, donde estaban ubicadas las ruinas del antiguo Estado Tiwanaku. El nombre de Tunupa representa en la estructura mitológica andina el "desorden"; a esta estructura mítica del desorden, relacionada en este caso con los vasos de oro del tupa cusi, se contrapone el tupa yauri como ele-

5 Según Bertonio 1984 [1612], en sus análisis del léxico colonial temprano, quero es: "Vaso para beber, de madera o plata, de cualquiera hechura que sea", aunque sabemos que estos vasos existieron desde el período Medio, tanto en la zona de influencia Wari como en la de Tiwanaku. También señala lo siguiente, Kero: madera, palos o vigas, y cosas semejantes; Aquilla: es lo mismo si es de plata o como taza; Kara quero: vaso que no tiene labor ninguna; Huakasjaquero: vaso que tiene como una cinta o faja en medio. Chaantacata quero: vaso que en los extremos tiene encajado estaño (véase Horta 2013: 100). Según lo resume Ziółkowski (1979), la expresión quero vicchi (cuba de madera) aparece en el diccionario de Santo Tomas (1951 [1560]), donde vicchi significa cuba pequeña o arcaduz, y quero es traducido como madero. Para Ricardo (1586) y Torres Rubio 1754 [1701] quero representa una taza de madera, un vaso de madera para beber o madero. Por último, González Holguín (1608) traduce quero como "vaso de madera" y qqueru como "trozo amplio o delgado de madera, todo material hecho por el leñador". Por lo tanto, originalmente la etimología de quero se relacionaba con un vaso de libación de madera denominado quero vicchi, luego a partir de la segunda mitad del siglo XVI vicchi cae en desuso y solo se mantiene la palabra quero (madera) para denominar tanto al material como al vaso (Ziółkowski 1979; Mulvany 2004). Rowe (1961), por su parte, presenta algunos términos no incluidos en los diccionarios de quechua, como katari keru traducido como "vaso con mango en forma de cabeza de puma", o qara keru traducido como "vaso no decorado" (Ziółkowski 1979). En nuestro caso utilizaremos la denominación quero pues la madera es el material de manufactura de las vasijas analizadas.

6 "Los indios le llamaban Ticiviracocha, pero, agrega Cieza [de León], en el collao se le llama Tuapaca y en otros sitios, Arnauan" (Duviols 1977: 59). 
mento contemporáneo propio del gobernante inca, que entrega el aspecto mítico dual, opuesto y complementario del "orden" (Cummins 2004). Para legitimar este (nuevo) orden dinástico de Manco Capac, simbolizado en el tupa yauri mítico del primer inca, esta compleja red de artefactos y elementos dinásticos además de estar sancionados por Viracocha, parecen estar intencionalmente relacionados con mitos precedentes de recreación de la humanidad que ocurren en Tiwanaku.

Estos mitos, según Duviols (1977) y Cummins (2004) fueron consignados por primera vez alrededor de 1550 por Cieza de León y Juan de Betanzos, y quizás configurados en tiempos preincas. En ellos se relata cómo después de convertida en piedra la humanidad anterior, fueron creados en el mismo material los progenitores de todos los ayllus y sus arquetipos étnicos para luego ser mandatados por Tici Viracocha Pachayachachic para surgir en cuevas, vertientes, cerros, etc., de diversos nichos ecológicos para utilizar y "heredar" allí el conocimiento entregado (Molina 1919 [1561]; Duviols 1977; Steel 2004). Estos antepasados pétreos fundacionales fueron confirmados en el origen de este nuevo tiempo por Viracocha para civilizar los Andes, situación que puede estar ligada con la cueva Tampu T'oqoy la presencia de Viracocha cerca de Pacaritambo para favorecer a Manco Capac de acuerdo a los planteamientos de Cummins (2004). Esta pretendida continuidad mitohistórica con Tiwanaku como fundamento presente de legitimación inca, probablemente conllevó diversos grados de asimilación cultural y material, entre los que pudo figurar la valoración de los monolitos propios del período Medio (500-1200 DC) y la parafernalia de las libaciones en queros (Cummins 2004).

De acuerdo a Cummins (2004: 102), hacia 1570 Diego de Alcobaza indagando el significado de las ruinas de Tiahuanaco ${ }^{7}$, los nativos locales hacían referencia a estatuas que representaban hombres "con vasos en sus manos" Estos monolitos monumentales propios del Horizonte Tiwanaku, representarían individuos de la elite local

7 Se hace la distinción entre las grafías de Tiahuanaco, que corresponden al sitio tipo, y Tiwanaku que corresponde al desarrollo cultural (Dauelsberg y Berenguer 1989).

8 La cita de Diego de Alcobaza es de una carta que reseña Garcilaso de la Vega en su obra Comentarios Reales de los Incas, Libro 3, Cap. I, pp. 213. que sostienen en sus manos vasijas que han sido identificadas como queros (Berenguer 1985, 1987; Cummins 2004). Interpretación muy probable ya que se considera que Tiwanaku inicia la tradición manufacturera del quero y, arqueológicamente, se han relacionado estos objetos con las interacciones materiales que el área nuclear estableció con los diversos enclaves bajo su influencia (Kolata 1993; Knobloch 2000; Owen y Goldstein 2001). De esta manera, los relatos de los vasos aquillas traídos del Collasuyo por Tunupa pueden ser intentos específicos de relacionar los aquillas incas con la tradición material de los vasos queros de Tiwanaku (Cummins 2004). Así, el origen del Estado inca podía ser conectado con un nivel mágico-religioso más profundo y prestigioso del "pasado cosmológico" andino, resignificándolo a su presente político y cosmológico mediante la sanción directa de Viracocha a Manco Capac en los orígenes míticos del Tawantinsuyo (Cummins 2004). Este fundamento de legitimidad que propone el gobierno dinástico inca tendría un correlato material, importante en el presente trabajo, visualizado en los aquillas y otras vasijas.

En este contexto, se ha propuesto una forma heráldica de iconografía geométrica (tocapus) para evocar aspectos mitohistóricos relacionados con el origen del linaje inca (Cummins 2004; Bray 2005; Lizárraga 2009; Horta 2013). Iconografía presente, entre otros, en prendas textiles, escudos, aríbalos y queros incisos. De ser ciertas estas hipótesis, en la fusión de aquellos aspectos relacionados con la forma de los queros y las decoraciones geométricas se han condensado, entonces, aspectos históricos de un pasado andino muy antiguo y otro más reciente; semántica mágico-religiosa que junto a otros artefactos (aríbalos, kipus, unkus o túnicas, textiles cumbi, etc.), actos y actores, servirían de soporte para la construcción y legitimación de la memoria dinástica inca. Así, cuando el inca asume su mandato le son presentados el tupa yauri y los tupa cusi, trayendo consigo una compleja red de mitos y relaciones artefactuales con Viracocha que simbolizaban, en última instancia, el desorden (tupa cusi) de un mundo que ha sido recreado y el orden (tupa yauri) que nace con el linaje de Manco Capac (Cummins 2004). Los vasos aquillas, que llevaba el primer inca al inicio de las conquistas territoriales, fueron activamente utilizados en el marco de la expansión estatal del Tawantinsuyo. Al respecto, Francisco de Toledo (1882 [1570-1572]) consigna que en la incorporación de la provincia de Jauja "el dicho 
Topa Ynga...había dado al dicho su bisagüelo (...) unas camisas y mantas galana y unos vasos que bebiese, que llaman entre ellos aquillas" (citado en Cummins 2004: 127). Mientras que Cieza de León consigna la presencia y regalo de estos vasos de oro en la anexión de una fracción del Collasuyo al Inca Viracocha, diciendo además que era habitual y que había construcciones conmemorativas que albergaban estos objetos.

"Y así los caciques y señores le salían de paz, y á éstos les hacía mercedes y daba vasos de oro y ropa del Cuzco..." (Santillán 1950 [1563]: 46-47).

En los orígenes míticos del Tawantinsuyo existe abundante evidencia documental que muestra una estrecha relación fundacional entre los vasos de oro en pares aquillas - del inca y su pretendida legitimidad mitohistórica; complejo simbólico que no es posible entender completamente sino se considera el brebaje contenido: la chicha.

\section{La chicha en el mundo inca}

Las chichas 9 en los Andes incluyen algunas de uso general como la chicha de maíz (Zea mays) y pimiento (Schinus molle), además de otras exclusivas de ciertas zonas como la chicha de chañar (tchaynar en lengua kunza; Geoffroea decorticans) y Prosopis sp. del área atacameña (Bibar 1558; Oña 1944 [1596]; Pardo y Pizarro 2005; Bonavia 2008). Sin embargo, de todas las chichas utilizadas en los Andes es la de maíz, la que tuvo mayor importancia histórica, alcanzando un clímax durante el Horizonte Inca (Dillehay 2003; Yoshida 2003; Cummins 2004; Pardo y Pizarro 2005; Jennings y Bowser 2009). Al respecto, Guaman Poma (1980 [1615]) ha consignado distintas ocasiones cuando se consumía la chicha en vasos pares: "cuando los inkas tomaban con el sol (antes de una guerra) (...); durante el Inti Raymi en junio (...); durante la siembra en

9 La chicha es una infusión de baja graduación alcohólica $\left(3^{\circ}-7^{\circ} \%\right.$ $\mathrm{v} / \mathrm{v}$ de etanol), posible gracias a la fermentación de azúcares libres que realizan los microorganismos (levaduras) presentes en la flora bucal y en los vegetales. El grado alcohólico de la bebida varía según el contenido de azúcares libres, las levaduras presentes, el tiempo de fermentación y la temperatura ambiente (Yoshida 2003; Jennings y Bowser 2009; Fula 2010; Chavarrea 2011). agosto (...); y por los ritos funerarios (de los inkas) (...) o de los Qollas" (Randall 1993: 75). Estas situaciones de índole colectiva y jerárquica que se suman a la asunción y casamiento del Inca o el mecanismo de dones para la anexión de territorio, formaban parte del año ritual agrícola y/o ritos fúnebres. Por tanto, son variadas las formas de expresión social del Estado donde se hicieron libaciones con chicha de maíz en vasos pares.

“...en semejantes fiestas el primer convite era del mayor al menor, en señal de merced y favor que el superior hacia al inferior. Donde a poco iba el inferior a convidar al superior, en reconocimiento de su vasallaje y servitud" (Garcilaso 2008 [1609]: 439-440).

Esta estructura jerárquica de las libaciones estatales conllevaba que cada participante tuviese su par de vasos y no "se bebía si no se estaba convidado, luego de lo cual el bebedor convidaba a su vez" (Betanzos 1956 [1653] citado en Saignes 1993). De igual manera, Garcilaso (2008 [1609]: 439) señala:

“...tienen los vasos para beber todos hermanados, de dos en dos: o sean grandes o chicos, han de ser de un tamaño, de una misma hechura, de un mismo metal, de oro o plata, o de madera. Y esto hacian porque hubiese igualdad en lo que se bebiese. El que convidaba a beber llevaba sus dos vasos en las manos, y si el convidado era de menor calidad la daba el vaso de la mano izquierda, y si de mayor o igual, el de la derecha, con más o menos comedimiento conforme al grado o calidad del uno y del otro, y luego bebían ambos a la par..."

Esta relación asimétrica en la performance ${ }^{10}$ del Inca del beber chicha de maíz en vasos pares, que deja en la cúspide el brindis del Sol (Figura 1), estaba enfatizado por el material del cual estaban hechos los vasos de los asistentes: oro, plata o madera, de acuerdo a la jerarquía social (Cummins 2004; Martínez 2008; Lizárraga 2009; Martínez et al. 2014). Según Cummins (2004) este mecanismo de exclusión social que funcionaba como un protocolo del acto de embriagarse en las libaciones estatales, fue confirmado al lexicógrafo Bertonio (1984 [1612]) por informantes aymara hablantes. Sin embargo,

10 Representación escénica en que la estética y el sujeto son centrales a la representación. 


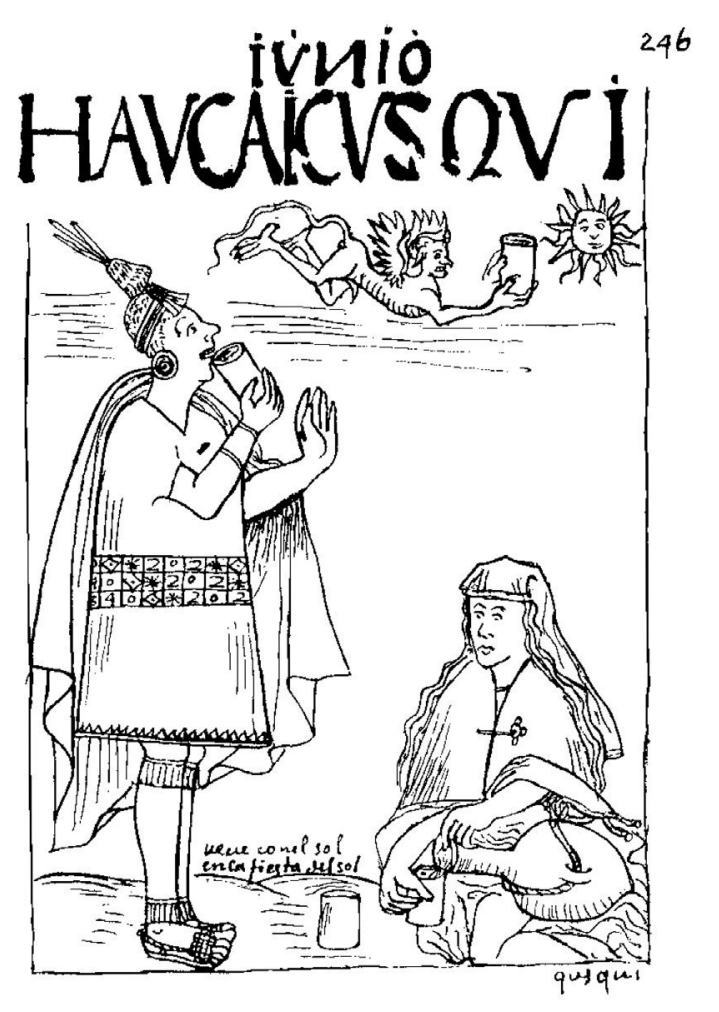

Junio / Haucaicusqui / bebe con el sol en la fiesta del sol.

Figura 1. Inca brindando con el sol. A sus pies una mujer llena un par de vasos queros.

es muy probable que este protocolo de los vasos pares para beber chicha de maíz, como muchas otras costumbres del Tawantinsuyo, tengan una compleja base panandina con elementos cotidianos regionales. Por ello, es menester hacer una distinción material en los contextos que son propios de las dinámicas del Estado inca, de aquellas otras oportunidades cotidianas $y / o$ inespecíficas como las chichas consumidas dentro de lógicas nutricionales y/o aquellas consumidas a propósito de oráculos, mingas locales, ritos fúnebres, etc.

Proponemos además que la tremenda imbricación cultural de la performance de la invitación recíproca a consumir chicha de maíz en vasos pares, que en el Tawantinsuyo se muestra socialmente asimétrica, es posible puesto que en los Andes esta ritualidad formó parte de un complejo soporte material de la memoria social (Saignes 1993). Esta memoria social está fuertemente relacionada con los ancestros. El cuidado de los difuntos era de vital importancia, tanto así que "al enterrar a los muertos dejaban un agujero en medio de la sepultura por donde en ciertos días le daban de beber chicha a los muertos" (Valcárcel 1978, en Cavero 1986: 40). Y "en noviembre sacaban a los difuntos en procesión, ofreciéndoles comida y bebida" (Cavero 1986: 40). Esta relación entre los difuntos, la borrachera y la memoria en el Perú son claramente visibles a más de medio siglo de evangelización, tal como se desprende del siguiente pasaje:

"Todas quantas borracheras juntays son en memoria de vuestras huacas, $y$ de vuestro antepasados, ... todo es ceremonia y memoria, y ritos del tiempo de vuestra infidelidad, ... todo es superstición de vuestras huacas, todos es enseñança de los viejos hechizeros" (Concilio Provincial de Lima 2001 [1585]: 376).

Las dinámicas de la memoria en el consumo de la chicha de maíz en los vasos pares muestra que la ceremonia de libación, recíproca pero asimétrica, durante el Tawantinsuyo debieron ser complejas. Pero también muestran que estas construcciones son sistémicas y que reposan sobre varios pilares sociales, artefactos, actos y actores que se relacionan en un determinado nivel subjetivo del individuo con el estado de su embriaguez. Puesto que "fuera de ciertos contextos permitidos (las grandes celebraciones y otros rituales colectivos) los estados de ebriedad eran severamente controlados y las personas ebrias eran frecuentemente condenadas a muerte" (Salazar-Soler 1993: 27).

A pesar de que hay diferencias en este tópico entre los diferentes cronistas, "desde la prohibición total para Garcilaso ... y con un castigo riguroso según Waman Puma ... a un uso limitado a grupos ligados al Estado (como los Curacas o yana) o, al contrario, público, bajo estricta vigilancia" (Saignes 1993: 46), es posible inferir en todas estas situaciones un control efectivo del Estado inca en la embriaguez del grupo. Por ello, el problema del estatus de la embriaguez no fue desconocido para los cronistas, toda vez que Santillán (1950 [1563]) consigna que los amautas instruyeron al Inca para diferenciar "entre cenca que es encalabriarse y hatun machay que es embriagarse hasta perder el juicio, y que de aquellos era lo ordinario [cenca] que en todos acontecia pues no hacían desatinos de locos y que aquesto [hatun machay] pocas veces o ninguno acontecia", mientras que González H. 1952 [1608] dice de cencca que es "medio borracho tocado assomado". 
El embriagarse en las libaciones estatales funcionaba como un mecanismo controlado de catarsis social que podía durar semanas y que usualmente terminaba en orgías, pleitos, etc., pero que a su vez relajaba las tensiones sociales de los grupos bajo la influencia del Tawantinsuyo (Saignes 1993). Elementos de orden y desorden (u orden invertido) presentes en la legitimación dinástica del Inca, que relacionan directamente el beber chicha de maíz en vasos pares con la intoxicación alcohólica del sujeto, aspecto que el Estado inca usó como elemento de exclusión social. De hecho, el beber mucha chicha de alto grado, sin perder la cabeza, era considerado según Cobo (1956 [1653]) "primordial en estos rituales y quizás caracterizaba el comportamiento de los miembros de los linajes aristocráticos". Y para este efecto "buscan y estiman las chichas que más embriagan y en su confección les suelen echar cosas fuertes para que más presto los derriben" (énfasis nuestro).

Randall (1993) da una buena descripción general de la preparación de la chicha de maíz, donde hemos resaltado aquellos aspectos que suponen una optimización de la graduación alcohólica:

"Se empieza con cualquier maíz desgranado, el cual se echa en un pozo de piedra y se cubre con las hojas secas (pánqa) de las mismas mazorcas. Encima se ponen piedras y se moja todo con agua, dejándolo germinar por diez días. Después se saca el maíz ya brotado (wiñapu - de wiñay, "crecer") y se lo seca un día al sol para luego hacerlo moler. La masa se agrega a una tinaja de cerámica grande (chunpa, urpu o raki) llena de agua, haciéndola hervir por dos minutos mientras que se la mueve lentamente. Se la deja por una noche, y a la mañana siguiente se la echa en una canasta (isanka) forrada con paja (ichu) o con hojas de pánqa. La isanka se coloca encima de una horqueta de madera que se llama chacana que está puesta encima de la boca de otro raki, en el cual el líquido (seqe) gotea. Una vez que el rakise llena con el seqe, se lo hace hervir de nuevo, agregando una gran cantidad de qonchu, que es el sedimento que queda de una chicha anterior, el cual hace fermentar al líquido del wiñapu, convirtiéndolo en aqha, o chicha. Fermenta mejor si se la hace hervir por mayor tiempo (hasta ocho horas); y es más fuerte si se la deja madurar por varios dias. Una vez fermentadas se acumula en el fondo del raki el sedimento que sobra del proceso, lo que viene a ser el qonchu para la próxima chicha" (Randall 1993: 77; énfasis nuestro).

El contenido de etanol como sustancia embriagante en la chicha depende de la metodología de preparación del fermentado, distinguiéndose en las áreas nucleares del Tawantinsuyo una chicha fuerte llamada sora hecha con el maíz germinado y cocido que se diferenciaba de aquella chicha menos embriagante de maíz mascado. Procesos como el pulverizado del maíz, el cocimiento y tamizado del vegetal, etc. son también aspectos técnicos destinados a optimizar la graduación alcohólica en la preparación de la chicha de maíz que fueron utilizados en libaciones estatales incas (Saignes 1993). Y estas libaciones, asimétricas del uso de los vasos pares, sirvieron como mecanismo de control y desorden que legitimaba y soportaba materialmente una memoria dinástica con raíz mitohistórica. Cristóbal de Molina (el cuzqueño, 1919 [1561) y Polo de Ondegardo (1940 [1609]) probablemente vieron esta performance funcionando, puesto que consignan que las libaciones estatales masivas con toda la pompa de tiempos del Tawantinsuyo transcurrieron libremente "algunos años después de nuestra venida", proponiéndose como límite el Concilio de 1551 (Duviols 1977: 111). Mientras que la imbricación de la chicha con otros espacios importantes del individuo como la nutrición permitió que se convirtiera en un elemento social "común y cotidiano" durante la Colonia, pero que concentró un tremendo potencial ritual solapado. Ciertamente, tal como los sacrificios con llamas cedieron paso a los sacrificios menos "visibles" de cuyes, es probable que la embriaguez y el mochar (ofrendar) (Arriaga 1968 [1621]) con chicha se convirtieran en un vehículo que hacía invisible otros rituales. Su monoconsumo minimizaba y/o camuflaba la ingestión de sustancias psicoactivas como los alucinógenos y su parafernalia (Saignes 1993). Estas mezclas con alucinógenos pudieron ser usadas en secreto, en movimientos sociales como el Taqui Onkoy y la reivindicación del culto a las huacas para producir su expresión escatológica social como "enfermedad de baile" religioso andino (Salazar-Soler 1993). Es decir, el dominio territorial del Tawantinsuyo cambió muchas de las particularidades panandinas existentes en torno a las 
libaciones con chicha, particularmente incorporando la chicha de sora, los queros incisos y la exclusión social en las libaciones ceremoniales. Sin embargo, en líneas generales durante la Colonia muchas de estas "formas sociales" continuaron siendo un vehículo semántico para la ritualidad en torno a la memoria del grupo (Concilio Provincial de Lima 2001 [1585]:374-375), vehículo que da cuenta de una optimización técnica en la generación de etanol y en la preparación de estos fermentados de maíz.

\section{Libación y queros en el Collasuyo y en el valle de Azapa}

La costa del extremo norte de Chile presenta un aspecto geográfico abrupto, pero con condiciones adecuadas para la supervivencia humana, donde sobresalen grandes acantilados y limitados recursos de agua dulce que se complementan con la gran diversidad marítima propia de la costa del Pacífico. Estos elementos permitieron una temprana adaptación del hombre a este entorno árido, donde los denominados Valles Occidentales como Lluta, Azapa, Chaca y Camarones favorecieron rutas de desplazamientos hacia la altiplanicie, así como migraciones desde el interior hacia la costa, generando una mayor disponibilidad de recursos (Dauelsberg 1972; Muñoz 1989; Horta 2010, entre otros). Estos valles pequeños permitieron el cultivo de maíz y fueron centrales en la expansión inca (Díaz y Bastías 2014). En este contexto geográfico, la manufactura o presencia de queros se inicia en el valle de Azapa durante el período Medio u Horizonte Tiwanaku (500-1200 DC) principalmente en soporte cerámico, mientras que a partir del período Intermedio Tardío o Desarrollo Regional (1200-1450 DC) los queros comienzan a manufacturarse principalmente en madera. De acuerdo a las tipologías construidas por Rowe (1961), Núñez (1963), Espoueys (1974) y Horta (2013) en el Collasuyo, entre el período Intermedio Tardío y período Tardío u Horizonte Inca, en el registro arqueológico local existieron al menos cinco tipos de vasos de madera que han sido definidos como queros, los cuales se resumen a continuación (Figuras 2a-g):

1) Queros tipo Arica I: presentan iconografía de lagartijas a manera de asa. Éstos son considerados de origen local y están presentes en el período Intermedio Tardío.

2) Queros tipo Arica II: presentan iconografía antropo-

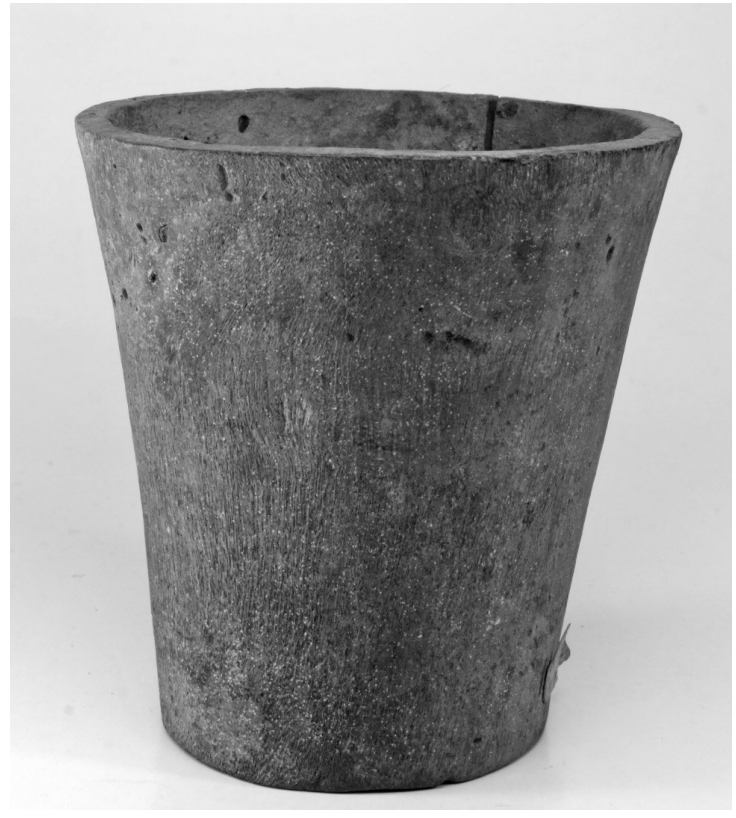

Figura 2a. Chaca 5, tumba 3, quero liso 765 . Dimensiones: alto externo base-borde: $11,3 \mathrm{~cm}$; ancho boca: $8,4 \mathrm{~cm}$; ancho base externa: $6,8 \mathrm{~cm}$; grosor pared: $0,6 \mathrm{~cm}$.

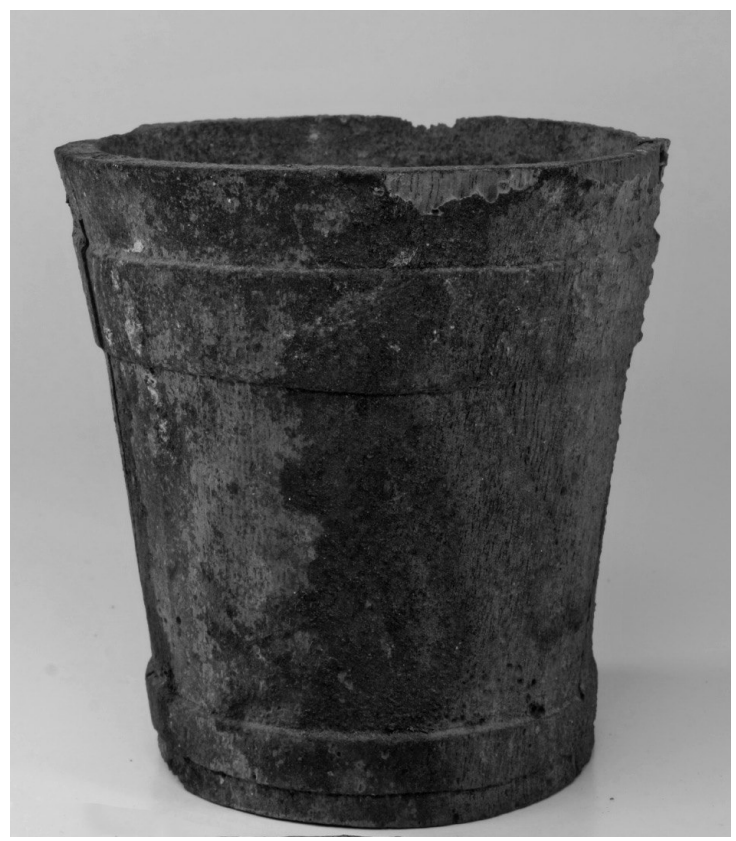

Figura 2b. Chaca 5, tumba 13, quero 1246 con bandas en sobrerelieve. Dimensiones: alto externo base borde: $10,9 \mathrm{~cm}$; ancho boca: $7,9 \mathrm{~cm}$; ancho base externa: 7,5 cm; grosor pared: $0,8 \mathrm{~cm}$. 


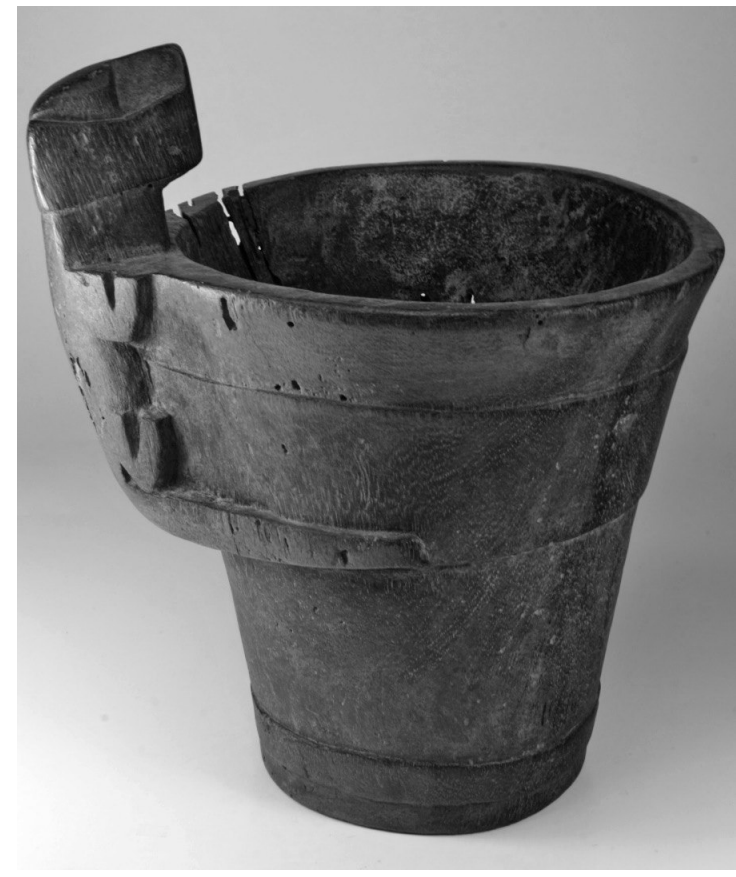

Figura 2c. Chaca 5, sin tumba, catari quero 767.1. Dimensiones: alto externo base-borde: $15,3 \mathrm{~cm}$; ancho boca: $12,3 \mathrm{~cm}$; ancho base externa: 9,1 cm; grosor pared: $1,0 \mathrm{~cm}$.

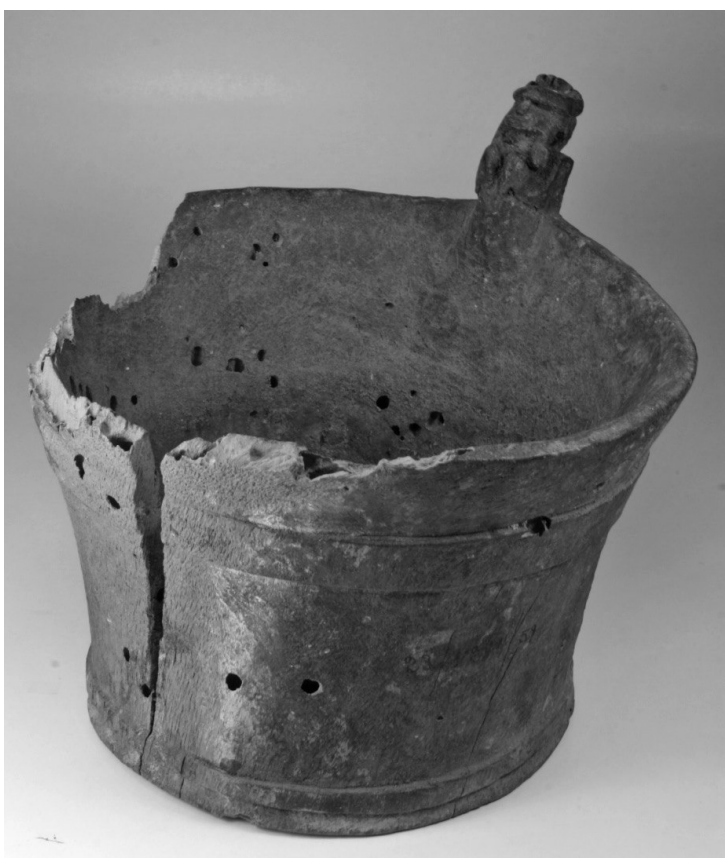

Figura 2d. Chaca 5, tumba 15, quero 1214 Arica II. Dimensiones: alto externo base-borde: 11, $0 \mathrm{~cm}$; ancho boca: $15,2 \mathrm{~cm}$; ancho base externa: $12,8 \mathrm{~cm}$; grosor pared: $0,7 \mathrm{~cm}$. morfa a manera de asa. Estos vasos son considerados de origen local y están presentes tanto en el período Intermedio Tardío como en el período Tardío.

3) Catari queros: presentan iconografía de felino a manera de asa. Son considerados como una tradición de influencia altiplánica y aparecen en el período Tardío (Horta 2013).

4) Queros incisos: tipos con iconografía geométrica incisa, los cuales son bienes escasos en el registro arqueológico local, de proveniencia inca y están presentes únicamente en el período Tardío.

5) Queros lisos: tipos que no presentan decoración. Son los más numerosos del registro arqueológico local, posiblemente inca (Horta 2013: 113) y están presenten en el período Tardío. Existirían dos subtipos troncocónicos: uno de paredes lisas y otro con dos bandas sobre relieve. Además existiría otro subtipo hiperbólico de paredes lisas.

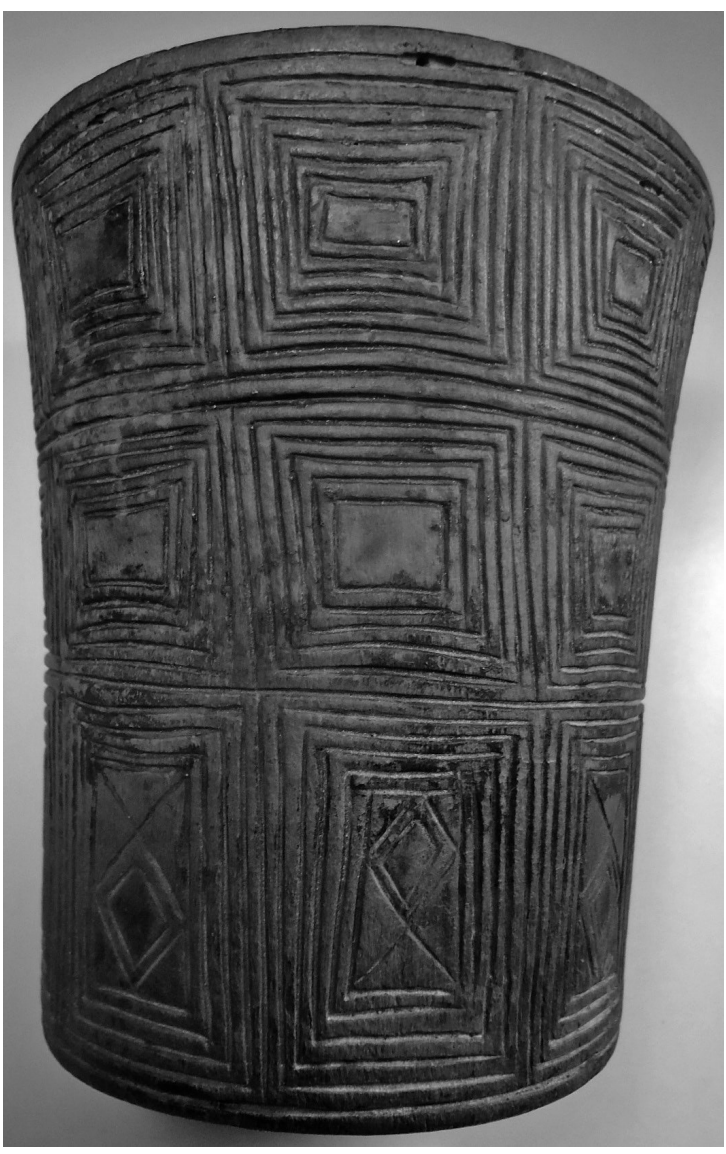

Figura 2e. Playa Miller 4, tumba 79, quero inciso 8156. Dimensiones: alto externo base-borde: $13,4 \mathrm{~cm}$; ancho boca: $10,4 \mathrm{~cm}$; ancho base externa: $9,2 \mathrm{~cm}$; grosor pared: $0,7 \mathrm{~cm}$. 


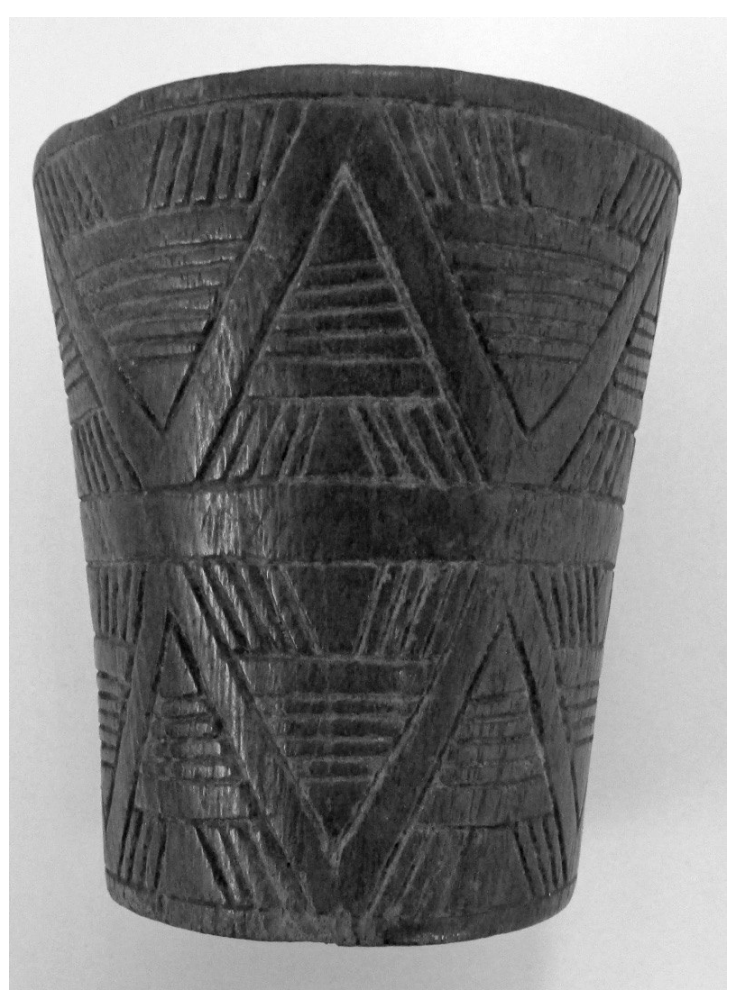

Figura 2f. Playa Miller 4, tumba 96, quero inciso 8539. Dimensiones: alto externo base-borde: $9,3 \mathrm{~cm}$; ancho boca: $6,0 \mathrm{~cm}$; ancho base externa: $5,9 \mathrm{~cm}$; grosor pared: $0,6 \mathrm{~cm}$. (Nota: muestra de sedimento insuficiente para análisis).

Proponemos, al igual que Horta (2013), que la escasa pero positiva presencia de queros de madera con iconografía geométrica incisa en cementerios propios del período Tardío podría estar relacionada con la heráldica inca. Según se observa en los diseños publicados por Rowe (1961, 1985), los especímenes excavados en Playa Miller-4 y Chaca-5, y estudiados en términos iconográficos por Horta (2013), son semejantes a aquellos queros de madera con iconografía incisa hallados en Ollantaytambo y la costa peruana ${ }^{11}$, lo cual permite preliminarmente una asociación estilística directa de estos artefactos encontrados en sitios locales con aquellos contextos estatales del área nuclear del Tawantinsuyo. Además, en los contextos de Ollantaytambo se han hallado queros de madera lisos hiperbólicos (Rowe 1961: 2; Cummins 2004), presentes también en el registro arqueológico local (Horta 2013). Por ello, la contemporaneidad de estos vasos de madera en contextos estatales incas y los contextos funerarios locales, permite preguntarse por aquellos aspectos materiales del uso de estos artefactos en relación a las libaciones con chicha de maíz durante el Horizonte Inca local.

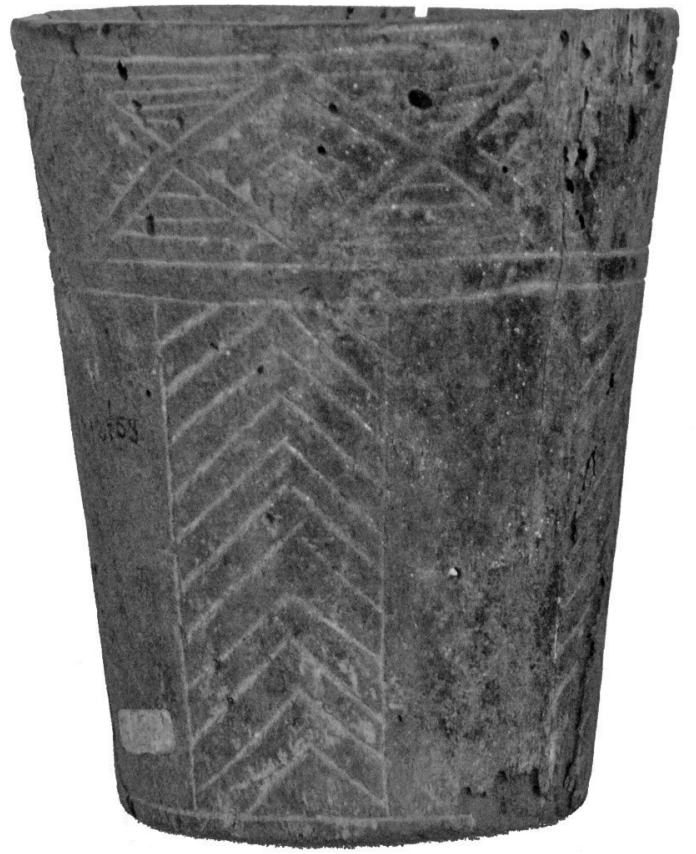

Figura 2g. Chaca 5, tumba 14, quero inciso 1257. Dimensiones: alto externo base-borde: 14,8 cm; ancho boca: $10,0 \mathrm{~cm}$; ancho base externa: $8,2 \mathrm{~cm}$; grosor pared: $0,7 \mathrm{~cm}$.

De esta manera, se propone el análisis de micro-restos arqueobotánicos presentes en el interior de los queros de madera para determinar si contienen granos de almidón de maíz y establecer el posible tratamiento que recibió para su fermentación. El análisis de estos resultados en el marco de la información ya relevada para las áreas nucleares del Tawantinsuyo, será utilizado para discutir la problemática mayor sobre las libaciones en el extremo norte de Chile durante el Horizonte Inca, considerando evidentemente el carácter regional del valle de Azapa en el Collasuyo.

11 El quero PLM-4 T79 8156 es similar a los vasos pares Ollantaytambo 5-738 y 5-739 (Rowe 1985). El caso Lluta-13 TC3-1 3110 (Horta 2013: 106) es similar al quero de Soniche UCMA 4-5096 del valle de Ica (Rowe 1985). El quero Chaca-5 T14 1257 es casi idéntico a los vasos pares Soniche UCMA 4-5097 y 4-5098 y además muy similar a los vasos Soniche UCMA 4-5099a y Soniche UCMA 4-5099b descritos por Rowe (1985). 


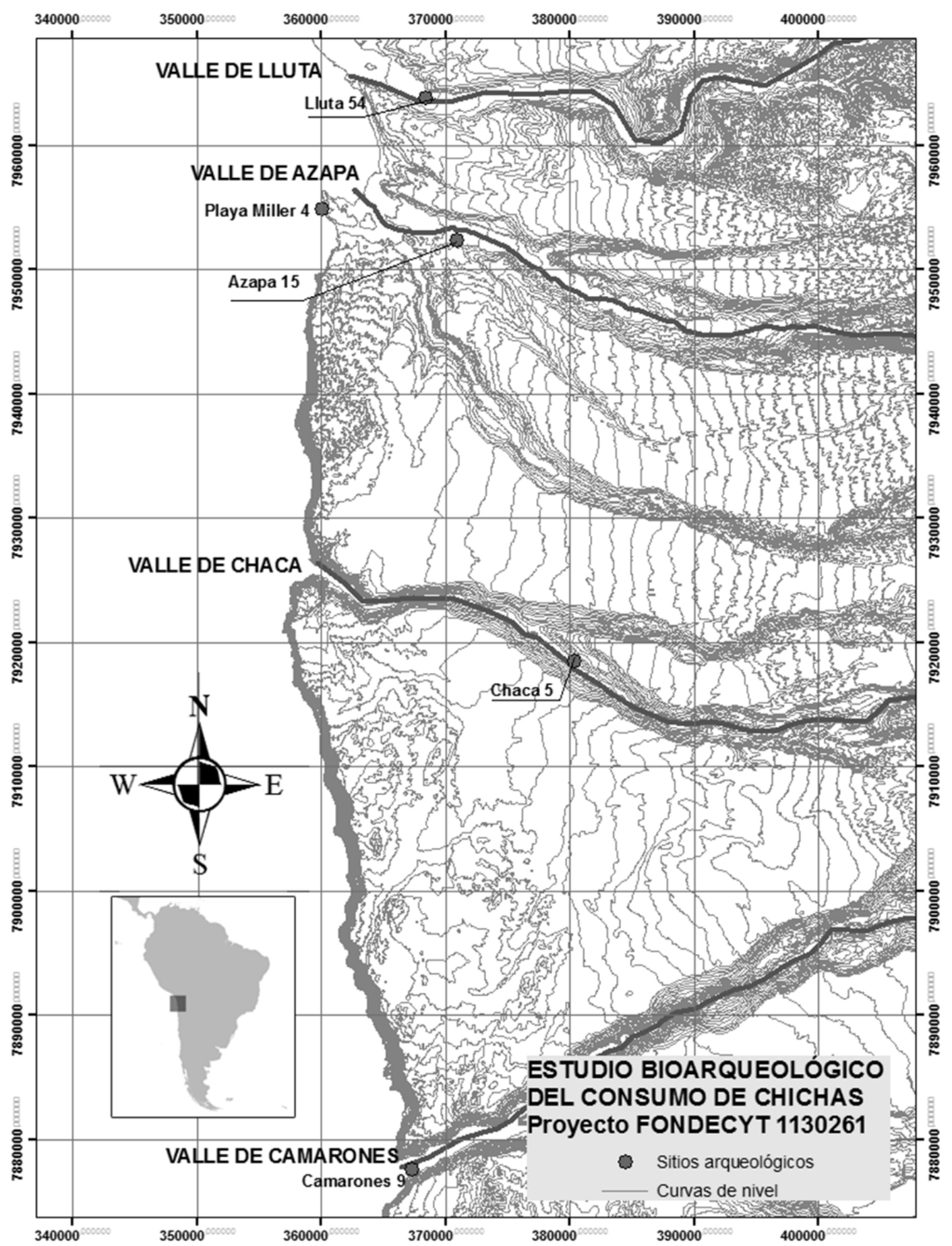

Figura 3. Mapa mostrando la distribución de los sitios en estudio. 


\section{$*$ Materiales}

Se estudiaron los sedimentos de 17 queros de maderas del período Intermedio Tardío y período Tardío de los cementerios Playa Miller-4, Azapa-15 y Chaca-5 (Tabla 1, Figura 3) que estuvieron disponibles para su análisis. Estos objetos se encuentran depositados en el Museo Arqueológico de la Universidad de Tarapacá San Miguel de Azapa (MASMA) en Arica. De estos queros, 10 son totalmente lisos, cinco presentan bandas o iconos y dos son incisos.

\section{* Metodología}

Utilizando guantes de látex sin talco y cepillos dentales con cabezal eléctrico removible, marca Colgate, modelo Motion, se procedió a cepillar el interior de las paredes y fondo de los queros de madera seleccionados para este estudio. Se trató de obtener al menos 0,5 g. de sedimento. Para la recolección y cepillado de cada muestra se utilizó un nuevo cabezal. Los sedimentos extraídos de cada quero, fueron almacenados en bolsas Ziploc previamente rotuladas.

Para la recuperación de granos de almidón a partir de los sedimentos se utilizó montaje directo y la metodología de Horrocks (2005), con la cual los granos de almidón se separan por gravimetría mediante el uso de bromuro de zinc a 1,8 g/ml de densidad. Finalmente, se analizó un volumen de $0,75 \mathrm{ml}$ por muestra utilizando una pipeta Pasteur desechable para extraer una gota de la solución y montarla en un portaobjeto con glicerina, análisis que se realizó por triplicado. El análisis microscópico para observar la birrefringencia característica de los granos de almidón (cruz de extinción) fue realizado en microscopios ópticos con luz polarizada, marca Olympus modelo BX41 y Zeiss modelo Axiostar, ambos con magnificación 40x. La fotografía de las muestras se realizó con cámara fotográfica marca Microimaging CCD-5 incorporada en el microscopio, mientras que la medición de los granos de almidón para contribuir a la identificación se ejecutó con el software Micrometrics SE Premium 4. El protocolo de recolección de muestras también incluyó el registro métrico y fotográfico de los 17 queros.

Los micro-restos arqueobotánicos analizados fueron contrastados con una colección de referencia local de granos de almidón de Zea mays generada para este proyecto y granos de almidón provenientes de una mazorca arqueológica (Chaca 5 T16 27476). La muestra comparativa de maíz moderno proviene del valle de Lluta (maíz lluteño) y fue sometida a distintas etapas de procesamiento, incluyendo trituración, cocción, tostado y fermentación. Además, para Zea mays y otras especies vegetales identificadas se utilizaron los patrones de referencia disponible en la literatura (Babot 2007a, b; Giovannetti et al. 2012; Huamán et al. 2014). Sin embargo, los análisis microscópicos se centraron en los granos de almidón del maíz, tratando de establecer las variaciones morfológicas que sufren estos polímeros de carbohidratos durante el proceso de fermentación. En el análisis de los granos de almidón y en su identificación se consideró la propuesta de Babot (2007b), Giovannetti et al. (2012), Giovanetti (2013) y Huamán et al. (2014), entre otros, donde se registró tamaño y morfología, incluyendo forma de los bordes e hilum. Las muestras fueron analizadas en el Laboratorio de Bioarqueología de la Universidad de Tarapacá en Arica, Chile y en el Laboratorio de Palinología y Paleobotánica de la Universidad Peruana Cayetano Heredia, Lima, Perú.

\begin{tabular}{|c|c|c|c|c|}
\hline $\mathbf{N}$ & Sitio & Área & $\begin{array}{l}\text { Tipo de Queroy } \\
\text { cantidad }\end{array}$ & Periodo \\
\hline 1 & Playa Miller-4 & Costa & Inciso $(\mathrm{N}=1)$ & $\begin{array}{l}\text { Intermedio Tardío, } \\
\text { Horizonte Inca }\end{array}$ \\
\hline 7 & Azapa-15 & Valle & $\begin{array}{l}\text { Liso }(\mathrm{N}=5) \\
\text { Catari }(\mathrm{N}=2)\end{array}$ & $\begin{array}{l}\text { Intermedio Tardío, } \\
\text { Horizonte Inca }\end{array}$ \\
\hline 9 & Chaca-5 & Valle & $\begin{array}{l}\text { Liso }(\mathrm{N}=5) \\
\text { Liso con bandas } \\
(\mathrm{N}=1)^{*} \quad \text { Inciso }(\mathrm{N}=1) \\
\text { Catari }(\mathrm{N}=1) \\
\text { Tipo Arica II }(\mathrm{N}=1)\end{array}$ & Horizonte Inca \\
\hline
\end{tabular}

Tabla 1. Resumen de queros analizados por sitio, área geográfica, tipo de vaso y periodo. Nota: ${ }^{*}$ Horta (2013) lo clasifica como quero liso y Espoueys (1974) como quero liso subtipo D1. 
Además, como control se analizaron muestras de guantes descartables de látex levemente entalcados, no estériles, marca Nipro, manufacturados en Malasia (Lote $\mathrm{N}^{\circ} 005058032000$ ), los cuales pueden ser utilizados en un museo durante el manejo de colecciones. Para ello se agregaron un par de gotas de agua destilada en la superficie interna del guante de látex y con una pipeta Pasteur se tomaron muestras que fueron montadas en un portaobjeto y observadas directamente en el microscopio. Posteriormente se realizó el mismo procedimiento de análisis para la parte externa del guante.

En cuanto al manejo de la información generada, se realizaron análisis de frecuencias, estadística descriptiva y multivariada dependiendo de la naturaleza de los datos. Para las variables cualitativas se realizó un análisis no paramétrico mediante test chi cuadrado de las frecuencias observadas de acuerdo a los diferentes criterios de clasificación. Debido a la gran cantidad de ceros en las celdas de las tablas cruzadas se seleccionaron y agruparon solo aquellas celdas que hacen más viable (especificación) el análisis, considerando que ninguna frecuencia esperada debe ser menor que uno, y no menos del 20\% de las frecuencias esperadas debe ser menos que cinco. En segunda instancia se compararon los diámetros de los granos de almidón de maíz para los criterios seco, triturado, tostado y fermentado, para lo cual se recurrió a técnicas paramétricas (Anova) y de distribución libre (Kruskal-Wallis), previa constatación de la normalidad (Shapiro Wilks) de los datos, y la post-hoc de Tukey para diferencias significativas $(\mathrm{P}<0,05)$. En ambos casos se utilizó un $95 \%$ de confianza y los softwares R, Minitab 16 y Excel 2010 (WinSTATS).

\begin{tabular}{|l|c|c|c|c|}
\hline Estadígrafo & Seco & Triturado & Fermentado & Tostado \\
\hline Media & 13,5 & 12,1 & 11,5 & 10,1 \\
\hline Mediana & 13,5 & 11,7 & 11,5 & 10,4 \\
\hline Moda & 14,4 & 10,5 & 11,5 & 10,5 \\
\hline $\begin{array}{l}\text { Desviación } \\
\text { estándar }\end{array}$ & 1,8 & 1,9 & 1,9 & 1,5 \\
\hline Mínimo & 10,4 & 9,3 & 8,1 & 8,0 \\
\hline Máximo & 17,5 & 17,4 & 16,0 & 16,4 \\
\hline Cuenta & 50,0 & 50,0 & 50,0 & 50,0 \\
\hline
\end{tabular}

Tabla 2. Estadística descriptiva del tamaño de granos de almidón de maíz lluteño actual (en $\mu \mathrm{m}$ ).

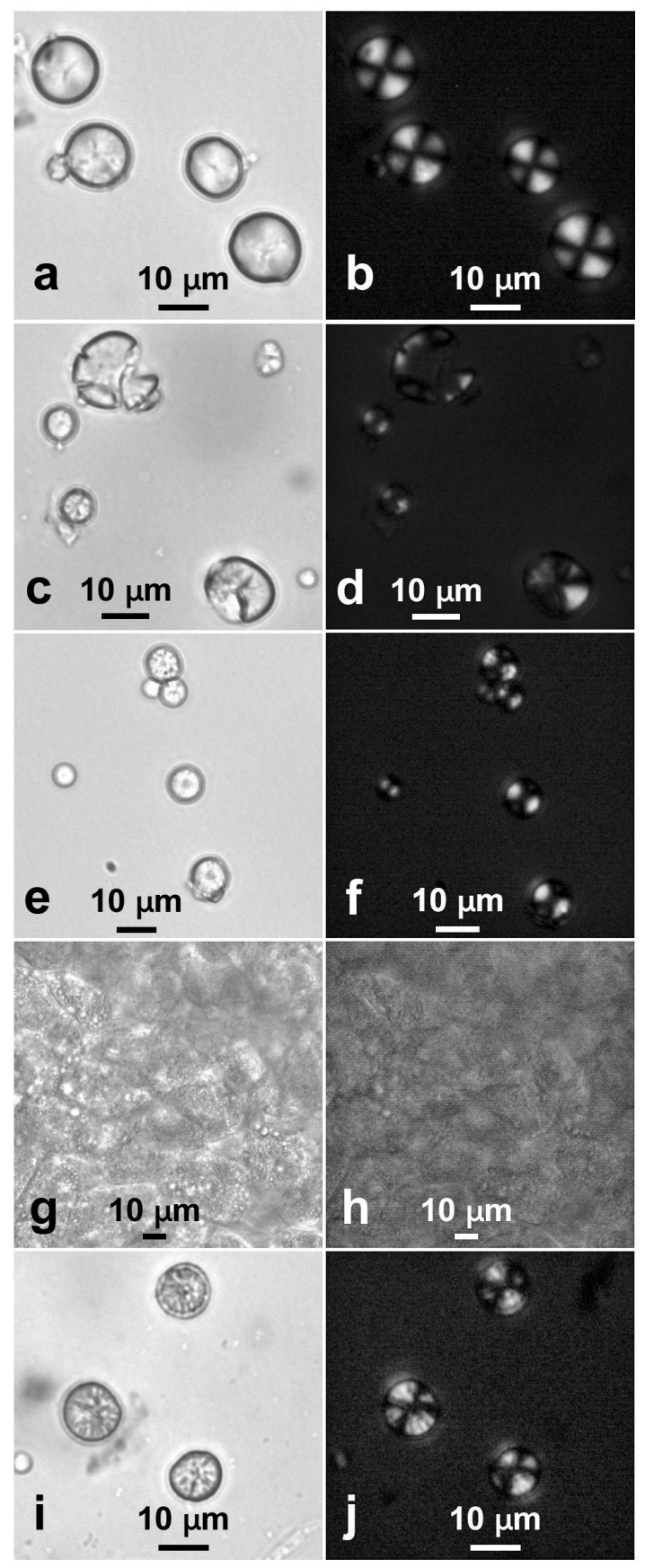

Figura 4. Granos de almidón de maíz lluteño actual, seco, 40X: a) sin alterar, campo claro, b) sin alterar, luz polarizada, c) triturado, campo claro, d) triturado, luz polarizada, e) tostado, campo claro, f) tostado luz polarizada, g) cocido, campo claro,

h) cocido, luz polarizada, i) fermentado, campo claro, j) fermentado, luz polarizada. 


\section{$*$ Resultados}

\section{Patrón de referencia de Zea mays}

Las Tablas 2-4 y Figura 4, presentan las características observadas en una muestra de 50 granos de almidón. Los principales resultados se resumen a continuación:

a) Granos de almidón normal (seco): granos de almidón sin alteración mecánica, térmica o fisicoquímica de Zea mays local, denominado lluteño. Los granos son esféricos y regular, con bordes normales y un diámetro promedio de 13,5 $\mu \mathrm{m}$ (DE: 1,8). El hilum tiene la forma de Y en la mayoría de los casos (46\%). Se observan estrías radiales en un $20 \%$ de la muestra y la morfología de la cruz es normal en el $80 \%$ de los casos (Figura 4a-b).

b) Granos de almidón triturado: poseen borde simple pero irregular con diámetro promedio de $12,1 \mu \mathrm{m}$ (DE: 1,9). El hilum es puntiforme en la mayoría de los casos (40\%). Se observan estrías radiales en el $22 \%$ de los casos y la morfología de la cruz de extinción es regular en un $88 \%$ de los casos (Figura $4 \mathrm{c}-\mathrm{d}$ ).

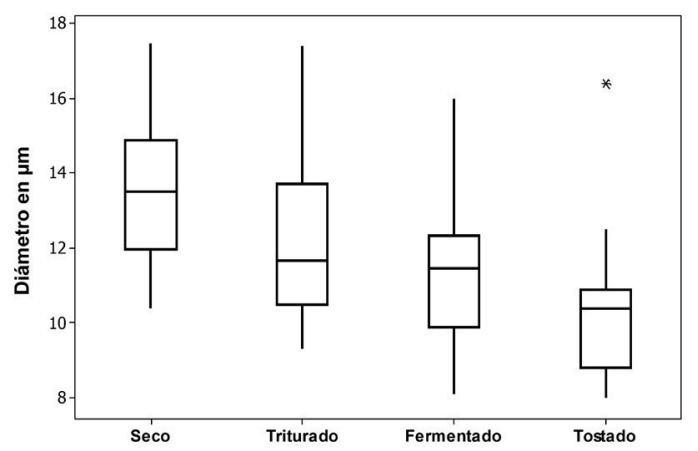

Figura 5. Variación en el tamaño del grano de almidón de maíz actual de acuerdo a varios tratamientos.

c) Granos de almidón tostado: conservan su forma esférica pero con bordes levemente irregulares y un diámetro promedio de 10,1 $\mu \mathrm{m}$ (DE: 1,5). El hilum es deforme y forma un círculo concéntrico y no es visible en el $88 \%$ de los casos. Presenta estrías radiales en $10 \%$ de los casos y la cruz de extinción es irregular en el $98 \%$ de los casos (Figura 4 e-f).

d) Granos cocidos (hervido): pierden totalmente su forma circular, gelatinificándose y aglomerándose. De igual forma pierden la cruz de extinción (birrefrigencia) la cual no es visible con luz polarizada (Figura 4g-h). e) Granos de almidón fermentado: presentan un diámetro promedio de 11,5 $\mu \mathrm{m}$ (DE: 1,9). En el 92\% de los casos no se observa la forma del hilum. Presentan estrías radiales en el $94 \%$ de los casos y la cruz de extinción es irregular en el 74\% de los casos (Figura 4i-j).

Las variables con datos suficientes para pruebas estadísticas fueron: tamaño del grano de almidón, formal del hilum, estrías radiales, morfología de la cruz y espesor de la cruz. Los análisis estadísticos de los granos de almidón del maíz actual, indican que las variables tamaño del grano de almidón, estrías radiales y espesor de la cruz son las que muestran diferencias significativas $(\mathrm{P}<0,05)$. En las muestras arqueológicas las variables que presentan diferencias significativas son: tamaño del grano, anillos, estrías radiales y brillo e intensidad de la luz. Sin embargo, desafortunadamente las frecuencias esperadas presentan conteos menores que cinco, invalidando el test de chi cuadrado (Tabla 3).

Para el caso del diámetro del almidón actual, las pruebas Anova como Kruskal-Wallis $(\mathrm{P}<0,05)$ detectaron diferencias significativas entre los distintos procesos a los que se sometieron los granos de almidón. En donde todos los granos tratados disminuyeron su tamaño. Estas diferencias significativas son ilustradas en la Figura 5 , representación de caja y bigotes (box and whiskers), donde el almidón tostado es el de menor tamaño, mientras que el triturado y el fermentado se asemejan entre sí según el test de Tukey.

\section{Guante de látex con almidón}

Los guantes de látex inspeccionados como fuente de contaminación dieron positivos en su cara interna mostrando abundantes granos de almidón aglomerados de diferentes tipos y tamaños. Entre los granos de almidón se destaca la presencia de maíz, papa, arroz y trigo. La cara externa del guante presentó mínima evidencia de granos de almidón (Figura 6).

\section{Muestra arqueológica}

La Tabla 4 identifica los queros de madera, sus principales características tipológicas, técnica de muestreo, cantidad de la muestra y los contenidos de macro-restos arqueobotánicos observados. En general los 17 queros analizados presentan escasos residuos adheridos a sus paredes internas; en este sentido se trató de llegar a los 


\begin{tabular}{|c|c|c|c|c|c|c|c|c|}
\hline & & \multicolumn{4}{|c|}{ Granos de almidón de maíz lluteño actual } & \multicolumn{3}{|c|}{ Granos de almidón de muestra arqueológica } \\
\hline 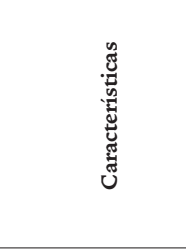 & Estados & 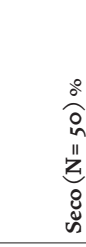 & 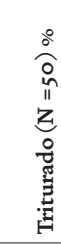 & 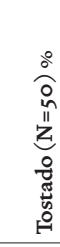 & 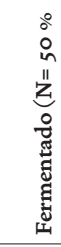 & 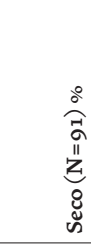 & 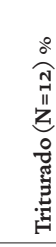 & 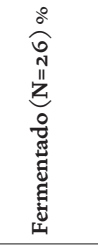 \\
\hline \multirow{6}{*}{$\begin{array}{l}\text { Morfología del } \\
\text { gránulo }\end{array}$} & $\begin{array}{l}\text { Circular/ } \\
\text { Subcircular }\end{array}$ & 100 & 100 & 100 & 100 & 100 & 100 & 92,3 \\
\hline & Oval/Suboval & o & o & o & o & o & o & 7,7 \\
\hline & Con cara recta & o & o & o & o & o & o & O \\
\hline & Polihédrico & O & o & o & o & o & O & O \\
\hline & $\begin{array}{l}\text { Sin forma definida } \\
\text { (irregular) }\end{array}$ & O & O & o & & O & o & O \\
\hline & Campaniforme & O & o & o & o & O & o & o \\
\hline \multirow{7}{*}{ Tamaño del gránulo } & Menor de $2 \mu$ & O & O & 0 & o & 0 & O & o \\
\hline & Entre $2-4 \mu$ & O & O & o & O & ० & O & o \\
\hline & Entre $4-6 \mu$ & O & O & o & O & O & O & O \\
\hline & Entre $6-8 \mu$ & ० & O & o & o & ० & O & o \\
\hline & Entre 8-10 $\mu$ & ० & 12 & 40 & 26 & 56 & 100 & 100 \\
\hline & \multirow{2}{*}{ Mayor de $1 \circ \mu$} & 100 & 88 & 60 & 24 & 44 & O & O \\
\hline & & \multicolumn{4}{|c|}{$X^{2}=28,6 ; G L=3 ; P<O, 001$} & \multicolumn{3}{|c|}{$\begin{array}{l}X^{2}=24,1 ; G L=2 ; P<O, O O ; \\
\text { Nota: } 1 \text { celda con valores esperados menores que } 5\end{array}$} \\
\hline \multirow[t]{5}{*}{ Forma del hilum } & No visible & 8 & o & 88 & 92 & 9,9 & 8,3 & o \\
\hline & Puntiforme & 34 & 40 & o & O & 90,1 & 91,7 & 69,2 \\
\hline & Filiforme & 12 & 26 & o & o & ० & O & 30,8 \\
\hline & & 46 & 34 & 12 & 8 & o & o & o \\
\hline & Lambda & \multicolumn{4}{|c|}{$\begin{array}{l}\text { Nota: } \mathrm{X}^{2} \text { no es válido, } 4 \text { celdas con conteos menores } \\
\text { que } 5\end{array}$} & \multicolumn{3}{|c|}{$X^{2}=1,939 ; G L=2 ; P=0,379$} \\
\hline \multirow{2}{*}{ Posición del hilum } & Central/Subcentral & 98 & 100 & 100 & 100 & 93,4 & 100 & 100 \\
\hline & Excéntrico & 2 & o & o & o & 6,5 & o & o \\
\hline \multirow{2}{*}{ Anillos } & No visible & 100 & 100 & 100 & 100 & 100 & 100 & 100 \\
\hline & Visible & ○ & ० & o & o & o & o & o \\
\hline \multirow{3}{*}{$\begin{array}{l}\text { Estrías } \\
\text { radiales }\end{array}$} & No visible & 80 & 78 & 90 & 6 & 100 & 100 & o \\
\hline & & 20 & 22 & 10 & 94 & o & O & 100 \\
\hline & visivie & \multicolumn{4}{|c|}{$X^{2}=96,8 ; G L=3 ; P<0,001$} & \multicolumn{3}{|c|}{$\begin{array}{l}\mathrm{X}^{2}=129 ; \mathrm{GL}=2 ; \mathrm{P}<\mathrm{O}, \mathrm{OO} 1 \\
\text { Nota: } 1 \text { celda con valores esperados menores que } 5\end{array}$} \\
\hline \multirow{2}{*}{ Borde o contorno } & Simple & 100 & 100 & 100 & 100 & 100 & 100 & 100 \\
\hline & Doble & o & o & o & o & o & o & o \\
\hline
\end{tabular}




\begin{tabular}{|c|c|c|c|c|c|c|c|c|}
\hline \multirow{3}{*}{$\begin{array}{l}\text { Morfología } \\
\text { de la cruz }\end{array}$} & Regular & 98 & 88 & 2 & 26 & 100 & 100 & o \\
\hline & $\begin{array}{l}\text { Irregular - Brazos } \\
\text { curvos }\end{array}$ & 2 & 12 & 98 & 74 & o & o & 100 \\
\hline & $\begin{array}{l}\text { Irregular - Brazos } \\
\text { quebrados }\end{array}$ & $\circ$ & $\circ$ & o & o & o & o & o \\
\hline \multirow{4}{*}{ Espesor de la cruz } & Delgado & $\circ$ & $\circ$ & $\circ$ & ○ & 97,8 & 91,7 & 69,2 \\
\hline & Intermedio & 94 & 96 & o & 100 & 2,2 & 8,3 & 30,8 \\
\hline & & 6 & 4 & 100 & o & ○ & $\circ$ & o \\
\hline & Grueso & \multicolumn{4}{|c|}{$X^{2}=176 ; G L=3 ; P<O, 001$} & \multicolumn{3}{|c|}{$\begin{array}{l}X^{2}=21,2 ; G L=2 ; P<O, 001 \\
\text { Nota: } 2 \text { celdas con conteos esperados menores que } 5\end{array}$} \\
\hline \multirow{4}{*}{$\begin{array}{l}\text { Brillo e intensidad } \\
\text { de la cruz }\end{array}$} & Suave & o & o & 96 & 94 & 38,5 & 100 & 100 \\
\hline & Moderado & 92 & 100 & 4 & 6 & 61,5 & o & o \\
\hline & & 8 & ○ & o & o & o & o & o \\
\hline & Fuerte & \multicolumn{4}{|c|}{$\begin{array}{l}\text { Nota: } \mathrm{X}^{2} \text { no es válido, } 4 \\
\text { celdas con conteos esperados menores que } 5\end{array}$} & \multicolumn{3}{|c|}{$\begin{array}{l}\mathrm{X}^{2}=37,6 ; \mathrm{GL}=2 ; \mathrm{P}<0,001 \\
\text { Nota: } 1 \text { celda con conteos esperados menores que } 5\end{array}$} \\
\hline
\end{tabular}

Tabla 3. Porcentaje en que se presenta cada estado de variable de los granos de almidón en los cariopsis del maíz lluteño y en sedimentos de queros arqueológicos.

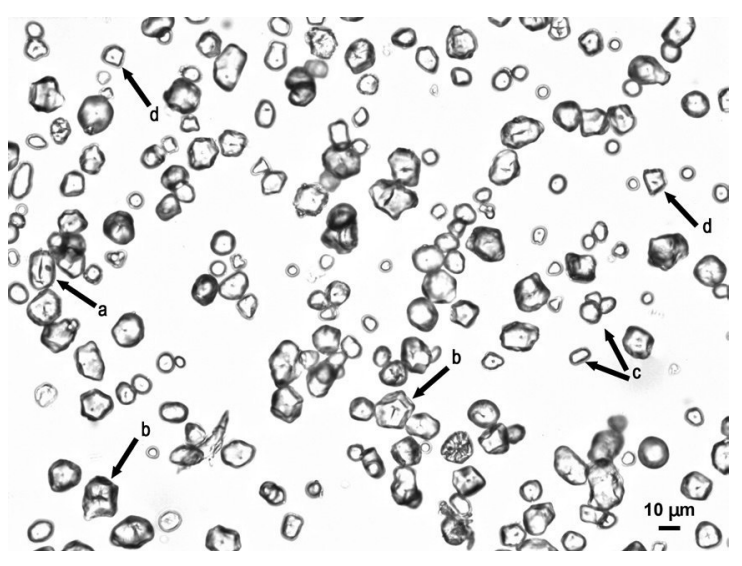

Figura 6. Presencia de granos de almidón en la cara interna de guantes de látex: a) papa, b) maíz, c) trigo y d) arroz. 4oX, campo claro.

intersticios de la madera cepillando las paredes. En un par de casos las vasijas aún contenían grandes cantidades de sedimento depositado en el fondo del quero, pero de igual manera se trató de muestrear residuos orgánicos adheridos a las paredes porque representarían los sedimentos de uso, en cambio los residuos más voluminosos podrían representar los sedimentos y suelos incorporados al quero durante el proceso de excavación.

Resumiendo los datos en forma general, se observa que el $88 \%(15 / 17)$ de los queros resultaron positivos para la presencia de granos de almidón y el $22 \%$ fueron negati- vos (2/17). De acuerdo a su clasificación tipológica, los cinco tipos de queros resultaron positivos para granos de almidón. Dividiendo todos los queros entre lisos $(n=11)$ y no lisos $(n=6)$, no se observan grandes diferencias en la presencia de granos de almidón: los primeros presentan un $81 \%(9 / 11)$ de casos positivos y los segundos $100 \%$ (6/6) (Tabla 4). Utilizando la morfometría del grano de almidón de maíz local como estándar de referencia y comparación, se obtuvo que el $88 \%$ (15/17) de los queros presentó micro-restos arqueobotánicos positivos para granos de almidón de Zea mays. En un 87\% (13/15) de los queros positivos se observaron granos de almidón de maíz sin evidencias de procesamiento (sin cocer, tostar o fermentar), los que fueron considerados como Zea mays crudo similar al de las mazorcas arqueológicas (Figura 7). De los queros positivos $(n=15)$, se considera que un $47 \%$ (7/15) presentaban posible contenido sedimentario de chicha de maíz (Figura 8, Tabla 4), diagnóstico basado en el borde irregular del grano de almidón y por grietas que llegan hasta el hilum. De igual forma, un $47 \%$ de los casos positivos fueron considerados como granos de almidón de maíz triturado, denotado por los bordes irregulares y cambios en el hilum. Sugerimos a manera de hipótesis que esta morfología podría estar relacionada con la preparación del maíz en forma de harina. Propuesta que necesita ser explorada y validada en futuros estudios. También es importante señalar que ninguno de los queros estudiados presentó granos de almidón tostado 

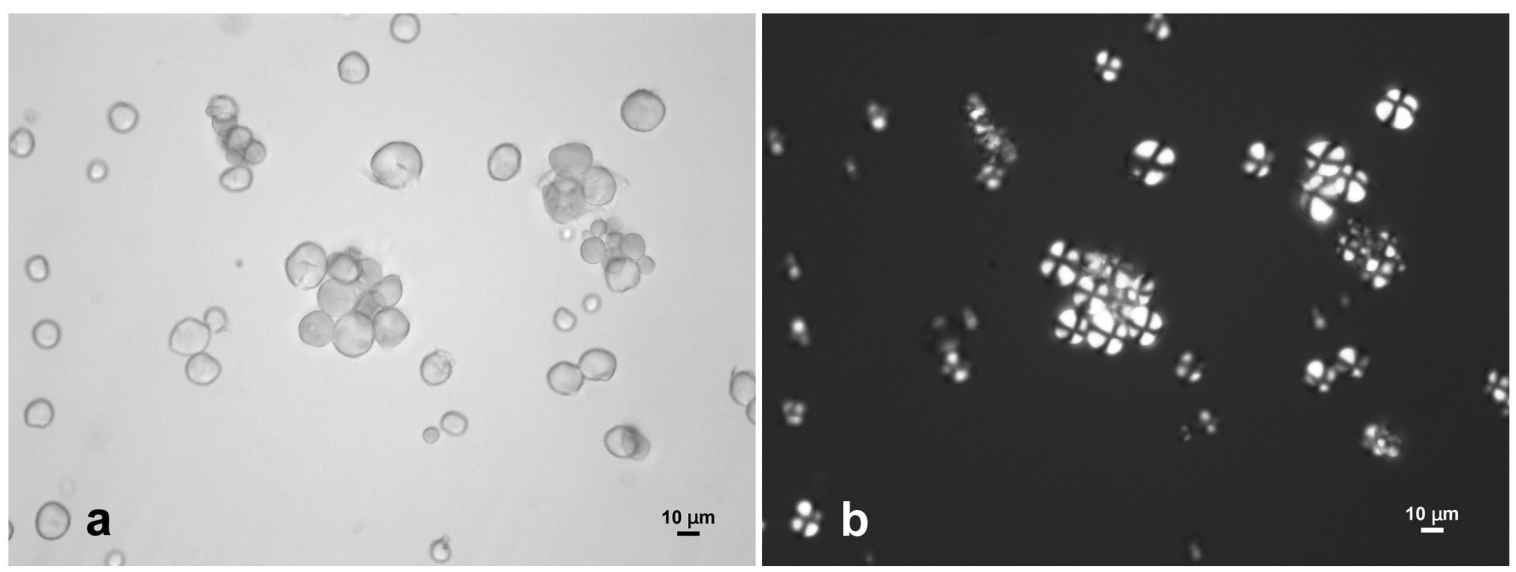

Figura 7. Granos de almidón de maíz, sin alterar, 40X, extraído directamente de una mazorca arqueológica 27476 de Chaca 5, tumba 16. a) Campo claro, b) luz polarizada.

ni cocido. Este último se caracteriza por la pérdida de la cruz de extinción y por encontrarse en proceso de gelatinización, perdiendo su forma y por lo que generalmente se le identifica en aglomerados amorfos (Figura $4 \mathrm{~g}$ - $\mathrm{h}$ ). Cabe señalar que también se encuentran grupos de granos de almidón aglomerados (crudos), pero en estos se preservan las estructuras características.

El grano de almidón de maíz (Zea mays) fue el más comúnmente hallado. Junto a este también se encontraron otros granos de almidón que fueron asignados a siete diferentes taxones, siendo el grano de almidón de frijol (Phaseolus vulgaris) el más común después del maíz (Tabla 4, Figura 9). Identificación basada en un patrón de referencia actual y en datos bibliográficos (Babot 2007a, b; Huamán et al. 2014). Al respecto, el grano de almidón del frijol tiende a ser oval y con una forma del hilum variable. Por último, se estima que el 60\% (9/15) de los queros positivos presentarían granos de almidón de frijol sin
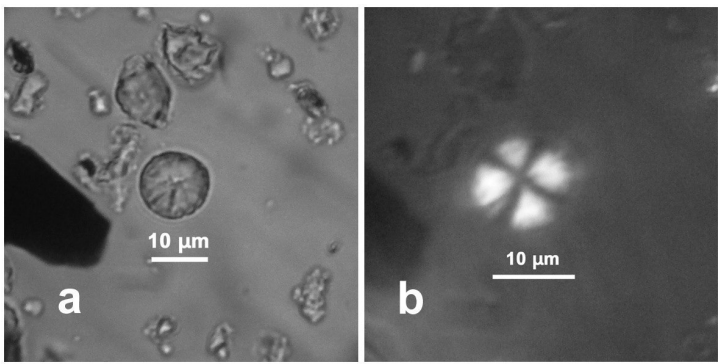

Figura 8. Grano de almidón de maíz fermentado, 40X. Extraído del quero 8156 de Playa Miller 4, tumba 79. a) Campo claro,

b) luz polarizada. modificar y el 13\% (2/15) de los vasos, granos triturados. Además, se observaron queros con otros granos de almidón (sin modificar), los que fueron clasificados como pallar con un 33\% (5/15) y yuca con un 20\% (3/15) (Figuras 10 y 11$)^{12}$.

\section{* Discusión}

La literatura arqueológica de las colecciones del MASMA consigna un total de 75 vasos de madera publicados, los cuales se distribuyen cronológicamente entre sitios del período Intermedio Tardío y período Tardío del norte de Chile (Espoueys 1974; Horta 2013). De los cinco tipos de queros de madera presentes en las colecciones del MASMA, por el momento, no fue posible analizarlos queros tipo Arica I, asociados al período Intermedio Tardío, mientras que sí se analizó el tipo Arica II (asociado también al período Intermedio Tardío), ya que evidencia continuidad en el Horizonte Inca. Los queros lisos e incisos aparecen solamente durante el período Tardío, cuando la variante lisa sin decoración se concentra en cementerios que comienzan a ser ocupados solo durante el Horizonte Inca (Rowe 1961; Núñez 1963; Espoueys 1974; Horta 2013). En este universo de 75 queros de madera, nueve de ellos (12\%) presentan decoración externa con icono-

12 Cabe señalar que estos taxones vegetales (Phaseolus lunatus "pallar" y Manihot esculenta "yuca") han sido anteriormente reportados como macro-restos en el registro arqueológico local (Erices 1975; Muñoz 2004). 
Estudio de almidones en Queros de madera del norte de Chile Relacionados Con el Consumo de CHICHA DURANTE EL HORIZONTE INCA

\begin{tabular}{|c|c|c|c|c|c|c|c|}
\hline Sitio & Referencia & Tipo de quero & Estado del almidón & $\begin{array}{l}\text { Evidencia } \\
\text { principal de } \\
\text { granos de } \\
\text { almidón }\end{array}$ & $\begin{array}{l}\text { Nombre } \\
\text { común }\end{array}$ & Masa (grs) & $\begin{array}{l}\text { Cepillado o } \\
\text { Sedimento }\end{array}$ \\
\hline Azapa-15 & $\mathrm{T}_{5} 3070$ & Liso & Negativo & Negativo & -- & $<0,01$ & Cepillado \\
\hline Azapa-15 & T11 2409 & Liso & $\begin{array}{l}\text { Frijol en montículo, } \\
\text { Maíz sin alterar y en } \\
\text { montículo }\end{array}$ & $\begin{array}{l}\text { Zea mays, Phaseolus } \\
\text { vulgaris, Cucurbita } \\
\text { sp.o Lagenaria sp.y } \\
\text { Prosopis sp. }\end{array}$ & $\begin{array}{l}\text { Maíz, frijol, } \\
\text { zapallo o } \\
\text { calabaza y } \\
\text { algarrobo }\end{array}$ & 3,6 & Sedimento \\
\hline Azapa-15 & T15 2449 & Liso & $\begin{array}{l}\text { Frijol sin alterar y } \\
\text { triturado, Maíz sin } \\
\text { alterar y en montículo }\end{array}$ & $\begin{array}{l}\text { Zea mays y Phaseolus } \\
\text { vulgaris }\end{array}$ & Maíz y frijol & 0,03 & Cepillado \\
\hline Azapa-15 & $\mathrm{T}_{42} 2838$ & Liso & $\begin{array}{l}\text { Maíz sin alterar, } \\
\text { fermentado, en } \\
\text { montículo y triturado }\end{array}$ & $\begin{array}{l}\text { Zea mays y Cucurbita } \\
\text { sp.o Lagenaria sp. }\end{array}$ & $\begin{array}{l}\text { Maíz y zapallo o } \\
\text { calabaza }\end{array}$ & 2 & Cepillado \\
\hline Azapa-15 & T82 4828 & $\begin{array}{l}\text { Con bandas superior } \\
\text { e inferior en relieve } \\
\text { y figura zoomorfa } \\
\text { en borde superior } \\
\text { (Catari quero) }\end{array}$ & $\begin{array}{l}\text { Frijol sin alterar y en } \\
\text { montículo, Maíz en } \\
\text { montículo, Maíz y } \\
\text { frijol agrupados }\end{array}$ & $\begin{array}{l}\text { Zea mays, Phaseolus } \\
\text { vulgaris, Phaseolus } \\
\text { lunatus y Manihot } \\
\text { esculenta }\end{array}$ & $\begin{array}{l}\text { Maíz, frijol, } \\
\text { pallar y yuca }\end{array}$ & $<0,01$ & Cepillado \\
\hline Azapa-15 & T82 4829 & $\begin{array}{l}\text { Con bandas superior } \\
\text { e inferior en relieve } \\
\text { y figura zoomorfa } \\
\text { en borde superior } \\
\text { (Catari quero) }\end{array}$ & $\begin{array}{l}\text { Frijol sin alterar, } \\
\text { Maíz sin alterar y en } \\
\text { montículo, Maíz y } \\
\text { frijol agrupados }\end{array}$ & $\begin{array}{l}\text { Zea mays, Phaseolus } \\
\text { vulgaris, Phaseolus } \\
\text { lunatusy Ipomoea } \\
\text { batatas }\end{array}$ & $\begin{array}{l}\text { Maíz, frijol, } \\
\text { pallar y camote }\end{array}$ & 0,02 & Cepillado \\
\hline Azapa-15 & T84 4876 & Liso & $\begin{array}{l}\text { Frijol sin alterar y } \\
\text { Maíz sin alterar }\end{array}$ & $\begin{array}{l}\text { Zea mays, Phaseolus } \\
\text { vulgaris, Phaseolus } \\
\text { lunatus, Manihot } \\
\text { esculenta e Ipomoea } \\
\text { batatas }\end{array}$ & $\begin{array}{l}\text { Maíz, frijol, } \\
\text { pallar, yuca, } \\
\text { camote, }\end{array}$ & $<0,01$ & Cepillado \\
\hline Chaca-5 & $\mathrm{T}_{3} 764$ & Liso & $\begin{array}{l}\text { Frijol sin alterar, } \\
\text { Maíz sin alterar, } \\
\text { fermentado, en } \\
\text { montículo y triturado }\end{array}$ & $\begin{array}{l}\text { Zea mays y Phaseolus } \\
\text { vulgaris }\end{array}$ & Maíz y frijol & 1,9 & Cepillado \\
\hline Chaca-5 & $T_{3} 765$ & Liso & $\begin{array}{l}\text { Frijol sin alterar, } \\
\text { Maíz sin alterar, } \\
\text { fermentado y en } \\
\text { montículo }\end{array}$ & $\begin{array}{l}\text { Zea mays y Phaseolus } \\
\text { vulgaris }\end{array}$ & Maíz y frijol & 0,3 & Cepillado \\
\hline Chaca-5 & 767.1 & $\begin{array}{l}\text { Con bandas superior } \\
\text { e inferior en relieve } \\
\text { y figura zoomorfa } \\
\text { en borde superior } \\
\text { (Catari quero) }\end{array}$ & $\begin{array}{l}\text { Frijol sin alterar, } \\
\text { Maíz sin alterary } \\
\text { fermentado }\end{array}$ & $\begin{array}{l}\text { Zea mays, Phaseolus } \\
\text { vulgaris y Phaseolus } \\
\text { lunatus, Cucurbita sp. } \\
\text { o Lagenaria sp. }\end{array}$ & $\begin{array}{l}\text { Maíz, frijol, } \\
\text { pallar, zapallo o } \\
\text { calabaza }\end{array}$ & 0,3 & Cepillado \\
\hline Chaca-5 & 700 & Liso & $\begin{array}{l}\text { Maíz fermentado y } \\
\text { triturado }\end{array}$ & $\begin{array}{l}\text { Zea mays y Cucurbita } \\
\text { sp.o Lagenaria sp. }\end{array}$ & $\begin{array}{l}\text { Maíz y zapallo o } \\
\text { calabaza }\end{array}$ & 0,7 & Cepillado \\
\hline Chaca-5 & 701 & Liso & $\begin{array}{l}\text { Frijol en montículo } \\
\text { y triturado, Maíz sin } \\
\text { alterar, fermentado, } \\
\text { en montículo y } \\
\text { triturado }\end{array}$ & $\begin{array}{l}\text { Zea mays, Phaseolus } \\
\text { vulgaris, Phaseolus } \\
\text { lunatus y Manihot } \\
\text { esculenta, Cucurbita } \\
\text { sp.o Lagenaria sp. }\end{array}$ & $\begin{array}{l}\text { Maíz, frijol, } \\
\text { pallar, yuca } \\
\text { y zapallo o } \\
\text { calabaza }\end{array}$ & 0,6 & Cepillado \\
\hline Chaca-5 & $\mathrm{T}_{13} 1246$ & $\begin{array}{l}\text { Liso, con bandas } \\
\text { superior e inferior } \\
\text { en relieve }\end{array}$ & $\begin{array}{l}\text { Frijol sin alterar, } \\
\text { Maíz sin alterar, en } \\
\text { montículo y triturado }\end{array}$ & $\begin{array}{l}\text { Zea mays, Phaseolus } \\
\text { vulgarisy Manihot } \\
\text { esculenta }\end{array}$ & $\begin{array}{l}\text { Maíz, frijol y } \\
\text { yuca }\end{array}$ & 0,5 & Cepillado \\
\hline Chaca-5 & T14 1257 & $\begin{array}{l}\text { Inciso, decoración } \\
\text { geométrica }\end{array}$ & $\begin{array}{l}\text { Frijol sin alterar y } \\
\text { Maíz sin alterar }\end{array}$ & $\begin{array}{l}\text { Zea mays, Phaseolus } \\
\text { vulgaris y Pouteria } \\
\text { lúcuma }\end{array}$ & $\begin{array}{l}\text { Maíz, frijol y } \\
\text { lúcuma, }\end{array}$ & 0,3 & Cepillado \\
\hline
\end{tabular}




\begin{tabular}{|l|l|l|l|l|l|l|l|}
\hline Chaca-5 & T15 1214 & $\begin{array}{l}\text { Con bandas superior } \\
\text { e inferior en relieve y } \\
\text { figura antropomorfa } \\
\text { en borde superior } \\
\text { (Arica II) }\end{array}$ & Maíz triturado & Zea mays & Maíz & Cepillado \\
\hline Chaca-5 & T19 1244 & Liso & Negativo & Negativo & - & 1,5 & Cepillado \\
\hline Playa Miller-4 & T79 8156 & $\begin{array}{l}\text { Inciso, decoración } \\
\text { geométrica }\end{array}$ & $\begin{array}{l}\text { Maíz sin alterar, } \\
\text { fermentado, en } \\
\text { montículo y triturado }\end{array}$ & $\begin{array}{l}\text { Zea maysy Cucurbita } \\
\text { sp.o Lagenaria sp. }\end{array}$ & $\begin{array}{l}\text { Maíz y zapallo o } \\
\text { calabaza }\end{array}$ & 17 & Sedimento \\
\hline
\end{tabular}

Tabla 4. Contexto de los queros analizados y principales granos de almidón observados.

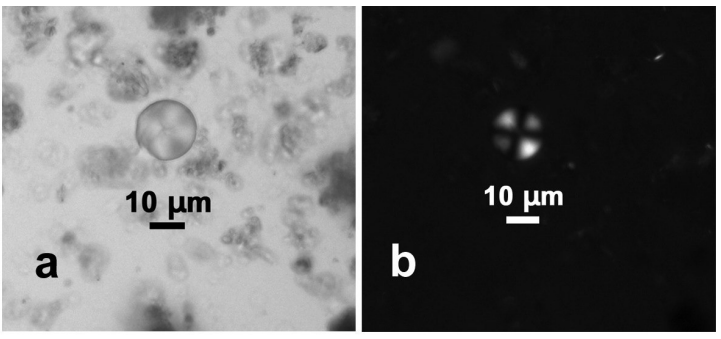

Figura 9. Grano de almidón de Phaseolus cf. sin alterar, 40X. Extraído del quero 1257 de Chaca 5, tumba 14. a) Campo claro, b) luz polarizada.
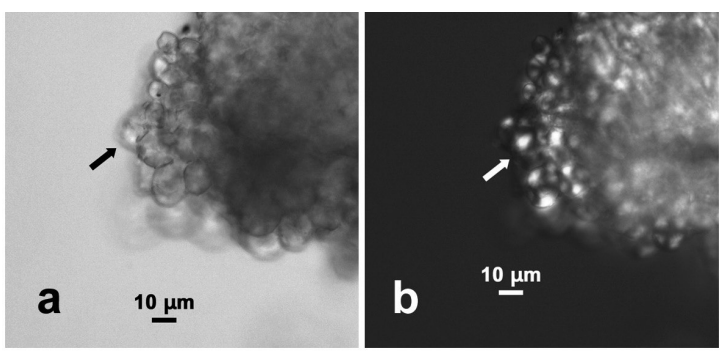

Figura 11. Aglomerado de granos almidón de maíz y grano de yuca (flecha), sin alterar, $40 X$. Contexto, quero 4828 de Azapa 15, tumba 82. a) Campo claro, b) luz polarizada.

grafía incisa, lo que los convierte en un bien escaso en las colecciones del norte de Chile, provenientes de cementerios del período Tardío que se encuentran tanto en la costa como en el valle. Por el contrario, los queros lisos sin decoración, que igualmente aparecen solo en cementerios del período Tardío, representan el 34,7\% (26/75) de los queros de madera depositados en el MASMA. Los catari queros representan un 10,7\% (8/75) del total, mientras que los queros Arica II representan el 15,8\% (12/75) (Horta 2013). Si bien no se cuenta con fechados absolutos para los queros, estos datos relacionados con los 17 vasos muestreados son interesantes, pues sugieren que los ejemplares con iconografía geométrica incisa y los catari queros son los artefactos más escasos, mientras que

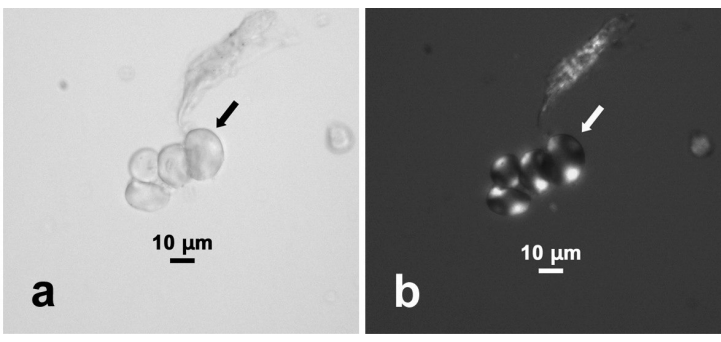

Figura 10. Granos de almidón de tres Phaseolus cf. y un pallar (flecha) sin alterar, 40X. Contexto, quero 4829 de Azapa 15, tumba 82. a) Campo claro, b) luz polarizada.

los queros troncocónicos de paredes lisas son los más comunes del Horizonte Inca y del ítem de queros de madera en general (Horta 2013). Cabe mencionar que también el quero liso con bandas y el subtipo hiperbólico, que es más fino, son escasos (Tabla 4).

El escaso hallazgo de vasos con iconografía geométrica incisa en el extremo norte de Chile, cuyos patrones estilísticos se encontraría según los especialistas asociados a contextos estatales de legitimación dinástica inca (Rowe 1961; Martínez 2008; Lizárraga 2009), podrían ser bienes de prestigio otorgados a los señores locales tal como se ha señalado en diversos estudios relacionados (Rowe 1961; Martínez 2008; Lizárraga 2009; Horta 2010, 2013). El hecho de que sean de madera evidentemente apunta a que independientemente de la diferenciación social que puedan indicar estas piezas decoradas, son de un orden periférico en relación a la parafernalia utilizada por el Estado inca. Sin embargo, aquellos aspectos regionales relacionados con la memoria del grupo y la naturaleza sistémica de las ceremonias de libación (carácter panandino), obligan a considerar las características de la libación local y tradicional para entender desde allí el impacto de las libaciones estatales incas. Al respecto, el posible origen altiplánico de los catari queros propuesto por 


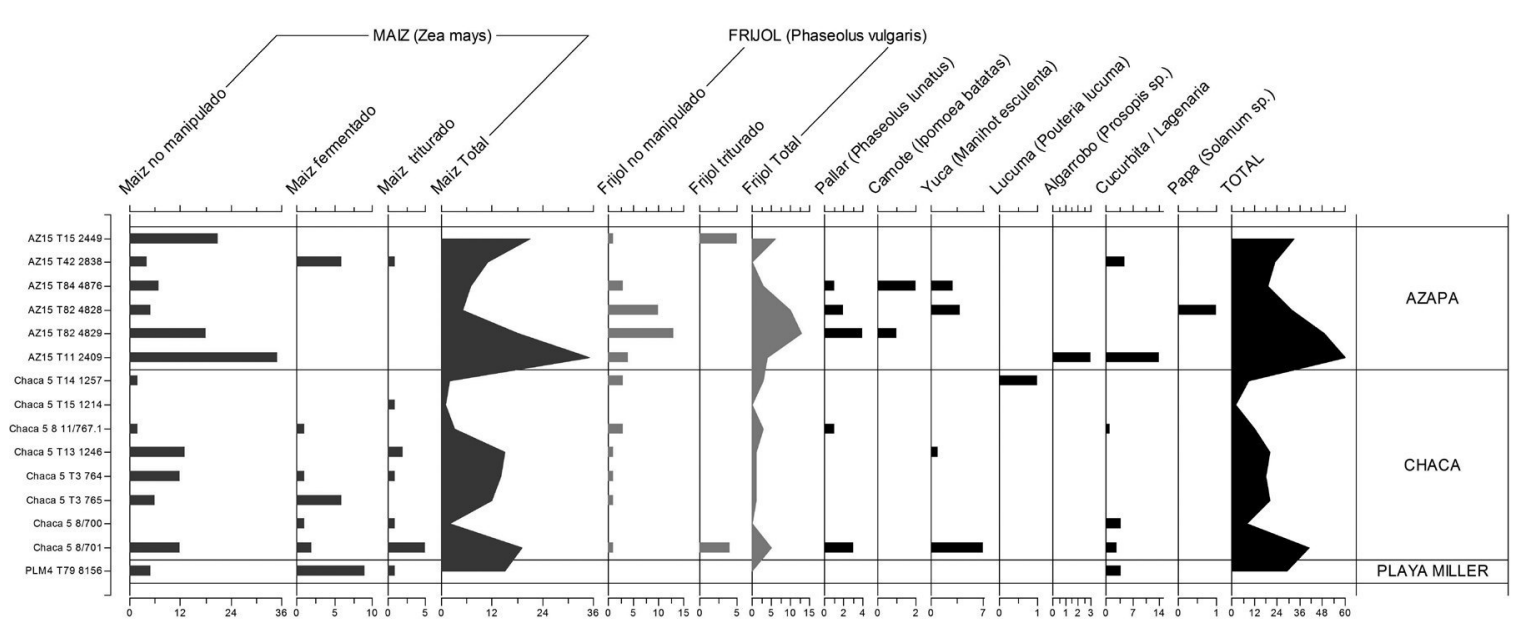

Figura 12. Distribución de granos de almidón por taxones encontrados en los queros analizados.

Horta (2013), hallados en cementerios del período Tardío a veces en los mismos contextos que los queros incisos, indica claramente la necesidad de incluir en este análisis sistémico de la libación local las relaciones míticas, sociales e históricas que las poblaciones del extremo norte de Chile mantuvieron con otras áreas del Collasuyo. Frente a ello, hay que considerar que la complejidad material de las libaciones redunda en artefactos cargados de simbología, donde una performance determinada de libación se podría haber configurado en múltiples soportes y niveles de abstracción. El origen de la madera con que se construyeron los distintos queros estudiados o una profundización de la iconografía geométrica de los queros incisos podría a futuro aportar otros niveles de interpretación y significado. A propósito, Kaplan et al. (1999: 32, en Lizárraga 2009) han sugerido que los queros incas habrían sido fabricados de madera de Prosopis.

El estudio de los queros de madera como objetos de libación debe ser matizado con la evidencia de su contenido, recordando que en este nivel hemos indagado en relación con los procesos de preparación de chicha a partir de Zea mays. Sin embargo, consideramos que la heterogeneidad en la masa y procedencia original de la muestra, más el bajo número de queros que tuvieron más de $0,5 \mathrm{mg}$ de sedimentos en las piezas revisadas en las colecciones del MASMA, no permiten profundizar en aspectos cuantitativos y en el análisis estadísticos más sofisticados de los datos. Por otro lado, el foco de interés es más bien cualitativo y tiene como objetivo estudiar los procesos de preparación de chicha a partir de Zea mays. Por ello, los criterios de interpretación de los granos de almidón arqueológico, por ahora, son fundamentalmente de ausencia versus presencia de los procesos. No obstante, aunque algunos resultados de las pruebas estadísticas no son robustas (celdas con frecuencias esperadas muy bajas), como tendencia se observa que las variables tamaño del gránulo y estrías radiales serían las que estadísticamente, independiente de la antigüedad del grano (actual versus arqueológico) podrían entregar información relevante.

En cuanto a los procesos y tamaño de los granos de almidón, es interesante señalar la importancia de computar las dimensiones de todos los granos de almidón arqueológico estudiado ya que los experimentos realizados con granos de almidón de maíz (actual y seco) presentan diferencias significativas cuando son sometidos a diversos tratamientos fisicoquímicos (Anova y Kruskal-Wallis P $<0,05)$. El diámetro del grano de almidón de maíz de la muestra de referencia disminuye significativamente su tamaño al ser sometido a trituración, fermentación y temperatura. Las dimensiones de los granos de almidón triturado y fermentado se asemejan entre sí, mientras que el tostado se agrupa de forma separada (Figura 5). En breve y como tendencia, se observa que el diámetro del almidón de la muestra de maíz señalada varía de la siguiente manera: seco > triturado > fermentado > tostado.

Respecto de los resultados del análisis de los granos de almidón presentes en los queros se han reconocido al menos ocho taxones distintos de vegetales (Figura 12, Tabla 4). Los datos apuntan a que los queros $-y$ por 
defecto la chicha - contenían la inclusión de otros tipos de vegetales (almidones) como una práctica común, independiente del tipo de quero, situación que amerita futuros estudios en otras muestras para validar este hallazgo. Además, la identificación de Zea mays indica que éste es el vegetal mayoritario en los diferentes queros analizados, donde el 86,6\% (13/15) de ellos presentó granos de almidón de maíz crudo o sin alteración (Figura 12). Solamente dos queros (lisos) fueron negativos para granos de almidón de cualquier taxón (Tabla 4). Consideramos que el 46,6\% (7/15) de los queros presentaron granos de almidón de maíz con evidencia de fermentación (Figura 8, Tabla 4), y el mismo porcentaje de queros presentaría granos de almidón con signos de chancado o triturado. Si bien estas observaciones y porcentajes pueden ser debatibles, es interesante que ninguno de los queros analizados presenta evidencia de granos de almidón de maíz cocido, lo que concuerda con los resultados de Dorsey et al. (2009), quienes estudiaron coprolitos del valle de Lluta de los períodos Intermedio Tardío y Horizonte Inca, y encontraron granos de almidón fermentados pero no cocidos en los micro-restos analizados. Estas evidencias sugieren la utilización de harinas o chancados para la fabricación de chichas de maíz, cuya preparación no incluye el cocimiento de las materias primas. Como ya hemos dicho, cocer la materia prima (granos, harina) antes de fermentarla facilita la extracción del almidón y azúcares creando una solución homogénea que favorece el proceso de fermentación. De igual manera, la cocción permite tamizar el contenido líquido contribuyendo a obtener chichas más limpias, maximiza la fermentación y permite una mayor duración del producto final. Estos procedimientos contribuirían a la producción de chichas más puras y de mayor graduación alcohólica (Fula 2010; Chavarrea 2011). De esta manera, el no cocimiento de la harina de maíz en el norte de Chile implica una corta vida de este tipo de fermentado y conlleva un método de menor eficacia para con los estados de intoxicación alcohólica. Estos resultados del área de Arica, marcan diferencias con la evidencia documental de las áreas nucleares del Tawantinsuyo, señalando que la fermentación de chichas duraderas de alta calidad y contenido etanólico, como la sora, era común para las castas nobles.

Dorsey et al. (2009) plantean que habría una baja en la frecuencia del almidón de maíz fermentado desde el período Intermedio Tardío al Horizonte Inca, lo que podría estar relacionado con un menor consumo de chicha de maíz. En el valle de Lluta durante el período Tardío hubo una mayor producción de este cereal, como se evidencia en la construcción a 8,4 km de la costa de numerosos silos para el almacenamiento de maíz, con un diámetro de 1,5 - 2 m y ca. 2 m de profundidad (Barraza y Cortez 1995; Díaz y Bastías 2014). Estos antecedentes pueden ser interpretados como una mayor producción de maíz y un menor consumo de chicha durante el Horizonte Inca (Dorsey et al. 2009). Por tanto, la divergencia en la preparación de la chicha de maíz local con respecto a aquellas producidas para las libaciones estatales, no significó que no hubiese un control sobre su consumo y/o la producción de Zea mays, características relacionadas con las libaciones del Tawantinsuyo. Al respecto, es interesante contrastar que si bien hubo un control local aparente sobre el consumo de chicha de maíz, la preparación del fermentado (no cocida), siguió un patrón diferente del estatal. Es decir, el impacto del Horizonte Inca se verifica en un control cuantitativo en torno a la producción y consumo de las materias primas como Zea mays, pero no en una influencia directa de aquellos aspectos cualitativos como es la preparación de la chicha de maíz.

Orgaz (2012) plantea para el sector sur del valle de Yocavil, área atacameña del noroeste argentino, que la presencia de restos de Prosopis sp. en las áreas donde se producían las libaciones durante el Horizonte Inca podría significar la negociación de identidades regionales fuertes, basadas en la tradición de fermentación local. Los resultados del norte de Chile muestran que esta "identidad de la embriaguez local" no solamente se construye con la fermentación de frutos locales, sino también con técnicas manufactureras que no son propias de la chicha que beben las elites incas en sus libaciones estatales. En este sentido, es importante recordarlas observaciones etnoarqueológicas de Hayashida (2008) sobre la existencia de diferencias culturales y regionales en el consumo y producción de las chichas en el norte de Perú. Por otro lado, en la medida que los análisis no pudieron demostrar lo contrario, todo lo planteado con respecto a la preparación de la chicha de maíz en el extremo norte de Chile involucra ciertamente los queros de madera con iconografía geométrica incisa. Estos aspectos, que bien pudiesen apuntar a los elementos locales que incorpora y utiliza la estructura sistémica de la libación en torno a la memoria del grupo, esconde más aún los posibles 
elementos estatales incas en el uso de estos queros. A la fecha, las evidencias de nuestro análisis no mostraron la presencia de cocimiento del maíz, como se esperaría en la denominada chicha sora. Sin embargo, no podemos descartar de plano la presencia de este tipo de chicha dado su escaso consumo masivo durante el año (p.e. Inti Raymi).

Otro aspecto a destacar es la presencia de otros vegetales en los distintos tipos de queros analizados. Este punto primero necesita de futuros trabajos arqueológicos que confirmen su identificación, así como verificar las variaciones morfométricas que sufre el almidón producto de los procesos de elaboración de las chichas. Luego, considerando el caso local de una chicha de maíz, sin cocimiento y de baja graduación alcohólica, es preciso dilucidar si los otros vegetales están orientados a una mejora del poder embriagante $\mathrm{o}$ a un aporte nutricional y/o medicinal de la chicha. En este sentido, es interesante destacar el alto número de queros que contenían evidencias de granos de almidón de Phaseolus sp., siendo el taxón con mayor recurrencia (11/15) después del Zea mays (Tabla 4). Cabe señalar que nueve de estas vasijas presentaban granos de almidón de frijol sin alteración y en dos casos signos de posible trituración. Considerando la mínima evidencia de granos de almidón de frijol fermentado, sugerimos que probablemente el frijol fue incorporado como harina o molido cuando estaba fresco. Por ende, planteamos a manera de hipótesis preliminar la inclusión de otros productos en forma de harinas, ya que se encontraron un número elevado de taxones vegetales en los queros cuando solamente se esperaba hallar maíz. Esto podría darse en el uso cotidiano de los queros analizados que probablemente contenían mezclas denominadas pihuelo o chupilca (Pardo y Pizarro 2005) o en ritos fúnebres locales; en particular en los ritos de "comer con el difunto", informados en las crónicas y etnográficamente. En estas prácticas rituales se iban agregando a una vasija o como parte de la ofrenda, aquellos alimentos que más gustaban al difunto (Poma de Ayala 1980 [1615];
Allen 2002; Hastorf 2003). Sobre este punto, cabe destacar que Espoueys y Henríquez (2010) encontraron evidencias de challa con granos de maíz y/o porotos en la excavación de Playa Miller 3 (véase además Horta 2010: 417-419) y un fardo funerario con signos de posible exhumación y reentierro durante el período Intermedio Tardío (caso Tumba 2 Unidad K-59).

En futuros análisis de sedimentos provenientes de nuevos hallazgos de queros habría que profundizar metodológicamente para corroborarla presencia de las diferentes taxas detectadas (distintas al maíz) y los posibles procesos a que fueron sometidos estas especies para su consumo, como fermentación, trituración, tostado, etc. En ambos casos, ya sea como aditivo nutricional (p.e. pihuelo) y/o ceremonial (p.e. comer con el difunto), el valor funcional de los vegetales adicionados a la chicha estaría relacionado con la dieta, sugiriendo que la mezcla es nutritiva más que embriagante. En este sentido, es interesante destacar la consistente relación del maíz con el frijol, puesto que la población del cementerio Chaca-5, de donde provienen la mayoría de los queros analizados, podría haber tenido una especialización en la producción de estos dos productos, tal como ha sido propuesto por Horta (2010: 457).

A pesar de lo limitado de los datos, si agrupamos los queros por tipo de forma (lisos y no lisos) versus los tipos de granos de almidón presentes, vemos que la inclusión de Zea mays fue independiente del tipo de quero (Tablas 4 y 5). Es decir, el 100\% (15/15) de los queros positivos presentan evidencia de Zea mays. También, resulta que no hay diferencias importantes en la cantidad de especies incorporadas por tipo de quero. De los queros lisos, tres de ellos presentaron dos especies de vegetales (granos de almidón de maíz y frijol) y seis casos presentaron más de dos especies de almidón Tabla5. Y en los queros no lisos, un caso presentó evidencia de granos de almidón de Zea mays, ninguno presentó dos especies y cinco casos presentaron más de tres especies de granos de almidón

\begin{tabular}{|l|c|c|c|c|c|c|c|c|}
\hline & Solo maíz & $\%$ & Maíz y frijol & $\%$ & $\begin{array}{c}\text { Maíz, frijoly otras } \\
\text { especies }\end{array}$ & $\%$ & Total queros & $\%$ \\
\hline Liso & 0 & 0 & 3 & 100 & 6 & 54,5 & 9 & 60 \\
\hline No liso & 1 & 100 & 0 & 0 & 5 & 45,5 & 6 & 40 \\
\hline Total & 1 & & 3 & & 11 & & 15 & \\
\hline
\end{tabular}

Tabla 5. Resumen de los principales granos de almidón por tipo de queros (solamente casos positivos). 
(Tablas 5 y 6). Considerando que la chicha consumida en el extremo norte de Chile era de una preparación simple u ordinaria (no cocida), y probablemente complementada con otros productos vegetales, pareciera que en este caso la ritualidad mortuoria prestaba más importancia al tipo, complejidad y origen del vaso ofrendado (inciso, catari) más que a la calidad del líquido que contenían.

Dado estos aspectos locales en torno a la libación con chicha de maíz en vasos queros de madera, complejos en su problematización y seguimiento empírico multinivelado, es un desafío evaluar la presencia material de libaciones estatales incas en los contextos regionales. Para avanzar en esta tarea, no solo debemos identificar los procesos a los cuales fueron sometidos los granos de almidón, sino que también a futuro es necesario caracterizar completamente la parafernalia arqueológica de preparación y consumo de la chicha de maíz local y establecer su posible correlato con el registro etnográfico del extremo norte de Chile de manera similar a lo realizado por Cremonte et al. (2009) para el noroeste argentino. Cabe señalar que futuros análisis químicos a los macro-restos arqueobotánicos estudiados (p.e. presencia de ácidos grasos específicos a cada planta, esterificación y ADN de las especies) podrían dilucidar qué vegetales habrían estado directamente relacionados con el proceso de fermentación y su optimización. De igual manera, los análisis demarcadores químicos del consumo de etanol en el cabello de los individuos del período Tardío podrían evidenciar diferencias significativas entre segmentos etarios, o eventos agudos de consumo de alcohol en el año, aspectos que permitirían a futuro evaluar la embriaguez en la población desde una perspectiva demográfica.

En algunos casos, la baja presencia de sedimentos en los queros y la ausencia de granos de almidón podría ser consecuencia de los tratamientos de limpieza a los que han sido sometidas las piezas con fines museográficos o de investigación. Por último, considerando que en diferentes momentos los investigadores y personal del museo utilizan guantes con talco para el manejo de las colecciones, algunos de estos datos presentados podrían ser objetados. Sin embargo, los análisis realizados en la parte interna de los guantes de látex revelan la presencia de granos de almidón de papa, maíz, trigo, arroz y una mínima presencia de estos en la parte externa. Por ello, señalamos que en los queros analizados no se encontraron granos de almidón que se asemejaran morfológicamente a la papa, trigo y arroz. Además, si resumimos el tamaño de los granos de almidón de varias plantas mencionadas en la Tabla 7 observamos la siguiente secuencia: Papa > Frijol $>$ Pallar $>$ Maíz $>$ Zapallo $>$ Calabaza $>$ Arroz $>$ Trigo . Los granos de almidón observados en los queros son de un diámetro mayor a $8 \mu \mathrm{m}$, lo que lo situaría en el valor medio de la secuencia señalada. Por otro lado, los granos de almidón de los queros presentan signos de fermentación, condición ausente en los granos de almidón observados en los guantes de látex. Finalmente las muestras de los queros provienen del cepillado de los sedimentos impregnados en las paredes de la madera, por lo tanto es muy probable que sean propios del uso del quero. Todo esto reflejaría una mínima contaminación antrópica producto de la manipulación anterior de las colecciones. No obstante estos argumentos, es altamente recomendable

\begin{tabular}{|c|c|c|c|c|c|c|c|}
\hline & \multicolumn{2}{|c|}{ Liso $(9+)$} & \multicolumn{5}{|c|}{ No liso $(6+)$} \\
\hline Estado & $\mathbf{N}^{\circ}$ almidones & $\begin{array}{c}\% \\
\mathrm{~N}^{\circ} \text { almidones } \\
\text { en liso }\end{array}$ & $\begin{array}{c}\text { Inciso, } \\
\mathrm{N}^{\mathrm{o}} \text { almidones }\end{array}$ & $\begin{array}{c}\text { Catari, } \\
\mathrm{N}^{\circ} \text { almidones }\end{array}$ & $\begin{array}{l}\text { Tipo Arica II, } \\
\mathrm{N}^{\circ} \text { almidones }\end{array}$ & $\begin{array}{c}\% \\
\mathrm{~N}^{\circ} \text { almidones } \\
\text { en no liso }\end{array}$ & $\begin{array}{c}\text { Total } \\
\mathrm{N}^{\circ} \text { almidones }\end{array}$ \\
\hline Sin alterar & 8 & 33,3 & 2 & 2 & $\mathrm{o}$ & 44,4 & 12 \\
\hline Triturado & 5 & 20,8 & 1 & o & 1 & 22,2 & 7 \\
\hline Cocido & o & $\circ$ & o & o & o & o & ० \\
\hline Fermentado & 5 & 20,8 & 1 & 1 & $\mathrm{O}$ & 22,2 & 7 \\
\hline Aglomerados & 6 & 25 & 1 & 2 & o & 33,3 & 9 \\
\hline Total & 24 & 100 & 5 & 5 & 1 & 100 & 35 \\
\hline
\end{tabular}

Tabla 6. Tratamiento de los granos de almidón de maíz por tipo de quero. 


\begin{tabular}{|c|c|c|c|c|c|}
\hline Especies & Nombre común & $\operatorname{Tamaño}(\mu \mathbf{m})$ & Forma & Forma del hilum & Referencia \\
\hline Solanum tuberosum $L$. & Papa & $14 \times 13$ a $80 \times 66$ & Ovoide, circular & Puntiforme, lineal & \multirow{6}{*}{$\begin{array}{c}\text { Torrence y Barton } \\
(2006), \text { Huamán et al. } \\
(2014)\end{array}$} \\
\hline Zea mays $L$. & Maíz & $5 \times 7$ a $15 \times 20$ & Circular, ovoide & Puntiforme, lineal, & \\
\hline Phaseolus vulgaris $L$. & Frijol & $20 \times 19$ a $61 \times 36$ & Circular, oval, arriñonada & Lineal, puntiforme. & \\
\hline Phaseolus lunatus $L$. & Pallar & $12 \times 13$ a $50 \times 40$ & Ovoide, circular, arriñonada & $\begin{array}{c}\text { Lineal, puntiforme, forma } \\
\text { "y" }\end{array}$ & \\
\hline Cucurbitasp. & Zapallo & $4 \times 5$ a $10 \times 11$ & Circular, ovoide & Puntiforme, lineal & \\
\hline Lagenaria sp. & Calabaza & $4 \times 5$ a $8 \times 10$ & Circular & Puntiforme, lineal & \\
\hline Triticum aestivum $L$. & Trigo & $3 \times 5$ a $7 \times 8$ & Poliédrico & Puntiforme, forma "y" & \multirow{2}{*}{$\begin{array}{l}\text { Torrence y Barton } \\
\quad(2006)\end{array}$} \\
\hline Oryza sativa $L$. & Arroz & $4 \times 5$ a $7 \times 10$ & Poliédrico & Lineal, forma " $y$ " & \\
\hline
\end{tabular}

Tabla 7. Tamaño y formas de algunos granos de almidón actual.

utilizar guantes sin talco para el manejo de las colecciones arqueológicas, minimizando con ello la contaminación antrópica.

\section{$*$ Conclusiones}

En el extremo norte de Chile, los queros de madera fueron contenedores utilizados para la ingesta de chichas de maíz no cocida. Aunque los datos son reducidos, estos sugieren que a la chicha de maíz le agregaban chancados o harinas de otros vegetales que no estaban cocidos ni fermentados. La inclusión de otros vegetales en la mayoría de los queros, complementarios al maíz, apunta a una práctica común y no a una situación aislada. Estos eventos de preparación e ingesta de fermentados de maíz probablemente reflejaron más las formas cotidianas de producción agrícola y ritualidad fúnebre de las poblaciones locales, antes que estrictas lógicas incas en las técnicas de preparación de chicha de alta graduación alcohólica para una libación estatal. Esta suerte de flexibilidad en el protocolo de la preparación y uso de la chicha de maíz en el ámbito local pudiera estar relacionada con la situación de periferia de los Valles Occidentales del extremo norte de Chile respecto de las áreas nucleares del Tawantinsuyo. Por ello, el conjunto de la evidencia nos lleva a plantear una presencia ambivalente del Estado inca en estos valles, posiblemente más interesado en la producción y consumo del Zea mays que en aquellos aspectos cualitativos de la preparación y simbolismo de la chicha de maíz en el ámbito local. Esta evidencia compartida en gran parte por la totalidad de piezas analizadas habla de la persistencia o visibilidad de una tradición local en torno al consumo de chicha de maíz que enmascara (hasta ahora) las posibles influencias de las libaciones estatales en el ámbito de la fermentación local.

En resumen, la negociación de lo local frente al impacto del Horizonte Inca, reflejada en los queros de madera y su contenido, muestra que la influencia estatal parece recaer localmente sobre aquellos aspectos cuantitativos (y de mayor escala) de la producción y consumo de Zea mays y en la parafernalia (queros decorados), más que en los aspectos relacionados con la calidad de las bebidas alcohólicas consumidas por las poblaciones periféricas del Tawantinsuyo. Si hubo libaciones estatales en el extremo norte de Chile, éstas no han dejado vestigios de una chicha cocida como la sora, situación que involucra incluso aquellos vasos que tendrían la mayor relación local con el Tawantinsuyo.

Agradecimientos Agradecemos formalmente al proyecto Fondecyt 1130261 titulado "Estudio bioarqueológico del consumo de chichas (bebidas alcohólicas) y su rol social en las poblaciones precolombinas del norte de Chile durante el Horizonte Inca, 1400-1500 d.C.); también a Natalia Aravena, Emilio Soto y Octavio Lagos por su asistencia en la fase experimental, registro de datos y procesamiento de imágenes. Igualmente agradecemos las críticas constructivas de los evaluadores anónimos y de la editora de Estudios Atacameños. 


\section{$\diamond$ Referencias Citadas}

ALLEN, C. 2002. The hold life has: coca and cultural identity in an Andean community. Smithsonian Books, Washington, D.C.

ARRIAGA, P. J. DE. 1968 [1621]. Extirpación de la Idolatría del Pirú. En Crónicas Peruanas de Interés Indígena, F. Esteve (Ed.). Ediciones Atlas, Madrid.

BABOT, M.P. 2007a. Análisis de caracteres macroscópicos y microscópicos de Phaseoleus vulgaris (Fabaceae, Fabiodae) silvestres y cultivados del Noroeste Argentino: una aplicación en arqueobotánica. Darwiniana 45 (2): 149-162.

BABOT, M.P. 2007b. Granos de almidón en contextos arqueológicos: posibilidades y perspectivas a partir de casos del Noroeste Argentino. En Paleoetnobotánica del Cono Sur: estudios de caso y propuestas metodológicas, M.B. Marconetto, M.P. Babot y N. Oliszewski (Eds.), pp. 95-125. Ferreyra Editor, Museo de Antropología de la Facultad de Filosofía y Humanidades, Universidad Nacional de Córdoba, Córdoba.

BARRAZA, J. y R. CORTEZ. 1995. Depósitos de alimentos en los valles de Azapa y Lluta (Período Prehispano Tardío). Actividad de titulación profesor de enseñanza media en Historia y Geografía, Universidad de Tarapacá, Arica.

BERENGUER, J. 1985. Evidencias de inhalación de alucinógenos en esculturas Tiwanaku. Chungara 14: 61-69.

BERENGUER, J. 1987. Consumo nasal de alucinógenos en Tiwanaku: una aproximación iconográfica. Boletín del Museo de Arte Precolombino 2:33-53.

BERENGUER, J. y P. DAUELSBERG. 1989. El Norte Grande en la órbita de Tiwanaku. En Culturas de Chile: prehistoria desde sus orígenes hasta los albores de la conquista, J. Hidalgo, V. Schiappacasse, H. Niemeyer, C. Aldunate, I. Solimano. (Eds.), pp. 129-180. Editorial Andrés Bello, Santiago de Chile.

BERTONIO, L. 1984 [1612]. Vocabulario de la lengua Aymara. Centro de Estudios de la Realidad Económica y Social (CERES), Instituto Francés de Estudios Andinos (IFEA), Cochabamba.

BETANZOS, J. 1987 [1551]. Suma y narración de los Incas Capacruna que fueron señores de Cuzco y de todo lo a ella subjetado. Editorial Atlas, Madrid.

BONAVIA, D. 2008. El maíz: su origen, su domesticación y el rol que ha cumplido en el desarrollo de la cultura. Universidad de San Martin de Porres, Fondo Editorial, Lima.
BRAY, T., L. MINC, M. C. CERUTI, J. CHÁVEZ, R. PEREA y J. REINHARD

2005. A compositional analysis of pottery vessels associated with the Inca ritual of Capacocha. Journal of Anthropological Archaeology $24(1): 82-100$.

CAVERO, R. 1986. Maiz, chicha y religiosidad andina. Universidad Nacional de San Cristóbal de Huamanga, Ayacucho.

CHAVARREA, M. 2011. Elaboración y conservación con fines agroindustriales y comerciales de la chicha de Jora y Quinoa en las comunidades beneficiarias del proyecto "Runa Kawsay". Trabajo de graduación de la Universidad Nacional de Chimborazo, Ecuador.

COBO, B. 1956 [1653]. Historia del Nuevo Mundo, BAE vol. 91-92. Ediciones Atlas, Madrid.

CONCILIO PROVINCIAL DE LIMA. 2001 [1585]. Tercero Catecismo y Exposición del Doctrina Cristiana, por Sermones. En El Discurso de la Evangelización del Siglo XVI. Instituto de Estudios Bolivianos, Universidad Mayor de San Andrés, La Paz.

CREMONTE, M.B., C. OTERO y M. S. GHEGGI. 2009. Reflexiones sobre el consumo de chicha en épocas prehispánicas a partir de un registro actual en Perchel (Dto. Tilcara, Jujuy). Relaciones de la Sociedad Argentina de Antropología XXXIV: 75-102.

CUMMINS, T. 2004. Brindis con el Inca: la abstracción andina y las imágenes coloniales de los queros. Fondo Editorial Universidad Nacional Mayor de San Marcos, Lima.

DAUELSBERG, P. 1972. Arqueología del Departamento. En Enciclopedia de Arica, pp. 161-178. Editorial de Enciclopedias Regionales, Santiago de Chile.

DÍAZ, A. y E. BASTÍAS. 2014. Lluta, historia de los cultivos del maíz en un valle salado: norte de Chile, A. Díaz y E. Bastías (Eds.). Ediciones Universidad de Tarapacá, Arica.

DILLEHAY, T. 2003. Colonialismo Inka, el consumo de chicha y los festines desde una perspectiva de banquetes políticos. Boletín de Arqueología, Pontificia Universidad Católica del Perú 7: 355-363.

DORSEY, S., L. PERRY, K. REINHARD, C. SANTORO y I. TEIXEIRA-SANTOS. 2009. Impact of empire expansion on household diet: The Inka in northern Chile's Atacama Desert. Plos One 4 (11): e8069. 
DUVIOLS, P. 1977. La Destrucción de las Religiones Andinas. (Conquista y Colonia). Instituto de Investigaciones Históricas, Universidad Autónoma de México, México.

ERICES, S. 1975. Evidencias de vegetales en tres cementerios prehispánicos, Arica-Chile. Chungara 5: 65-71.

ESPOUEYS, O. 1974. Tipificación de keros de madera de Arica. Chungara 4:39-54.

ESPOUEYS, O. y M. HENRÍQUEZ. 2006. Las excavaciones arqueológicas de Playa Miller 3, Temporada 2006. Informe final proyecto Fondecyt 1050279 titulado "Patrones de deformación intencional del cráneo en poblaciones prehispánicas de Arica. Análisis de morfometría geométrica con uso de telerradiografía craneofacial". (Documento inédito).

FERNÁNDEZ DE OVIEDO, G. 1959 [1535]. Historia General y Natural de las Indias. Ediciones Atlas, Madrid.

FULA, A. 2010. Desarrollo de una bebida fermentada con adición de cocción de maíz. Trabajo de grado. Universidad Nacional de Colombia, Bogotá.

GARCILASO DE LA VEGA, I. 2008 [1609]. Comentarios reales de los Incas. A.F.A. Editores Importadores S.A, Lima.

GIOVANNETTI, M., I. LANTOS, R. DEFACIO y N. RATTO. 2012. Construcción de un banco de almidones de variedades nativas de Zea Mays L. del noroeste Argentino. Propuesta metodológica y primeros resultados. En Las manos en la masa. Arqueologías, antropologías e historias de la alimentación en Suramérica, M. P. Babot, M. Marschoff y F. Pazzarelli (Eds.), pp. 361-385. Universidad Nacional de Córdoba, Museo de Antropología, Córdoba.

GIOVANNETTI, M. 2013. Propuesta para la recolección de microvestigios arqueobotánicos en morteros fijos. Comechingonia 17: 189-199.

GONZÁLEZ HOLGUIN, D. 1952 [1608]. Vocabulario de la lengua general de todo el Perú, llamada qquichua o del Inca. Universidad Nacional Mayor de San Marcos, Lima.

HASTORF, C. 2003. Andean luxury foods: special food for the ancestors, deities and the élite. Antiquity 77 (297): 545-554.

HAYASHIDA, F. 2008. Ancient beer and modern brewers: Ethnoarchaeological observations of chicha production in two regions of the North Coast of Peru. Journal of Anthropological Archaeology 27: 161-174.

HORROCKS, M. 2005. A combined procedure for recovering phytoliths and starch residues from soils, sedimentary deposits and similar materials. Journal of Archaeological Science 32 (8): 1169-1175.
HORTA, H. 2010. El señorío Arica y los reinos altiplánicos: Complementariedad ecológica y multietnicidad durante los siglos pre-conquista en el norte de Chile (1000-1540 DC). Tesis doctoral. Programa de Doctorado en Historia, mención Etnohistoria, Facultad de Filosofía y Humanidades, Universidad de Chile, Santiago.

HORTA, H. 2013. Queros de madera del Collasuyo: nuevos datos arqueológicos para definir tradiciones (siglos XIV-XVI). Estudios Atacameños 45: 95-116.

HUAMÁN, L., I. CASTILLO, M. PABLO, M. VELÁSQUEZ. 2014. Catálogo de granos de almidón de plantas útiles del Perú [Manuscrito]. Laboratorio de Palinología y Paleobotánica, Universidad Peruana Cayetano Heredia, Lima.

JENNINGS, J. y BOWSER, B. 2009. Drink, power, and society in the Andes, J. Jennings y B. Bowser (Eds.). University Press of Florida, Florida City.

KAPLAN, E., E. PEARLSTEIN, E. HOWE y J. LEVINSON. 1999. Qeros. Análisis técnico de los qeros pintados de los períodos Inka y colonial. Íconos. Revista peruana de conservación, arte y arqueología 2: 30-38.

KNOBLOCH, P. 2000. La cronología de contacto y encuentros cercanos de Wari. El caso de Conchopata, Ayacucho, Perú. Boletín de Arqueología, Pontificia Universidad Católica del Perú 4: 69-87.

KOLATA, A. 1993. The Tiwanaku: Portrait of an Andean Civilization. Blackwell, Cambridge.

LIZÁRRAGA, M. 2009. Las élites Andinas coloniales y la materialización de sus memorias particulares en los "queros de la transición" (vasos de madera del siglo XVI). Boletín del Museo Chileno de Arte Precolombino 14 (1): 37-53.

MARTÍNEZ, J. 2008. Pensar y representarse: aproximaciones a algunas prácticas coloniales Andinas de los siglos XVI y XVII. En Lenguajes visuales de los incas. P. González Carvajal y T. Bray (Eds.), pp. 147-161. Archaeopress, Oxford.

MARTÍNEZ, J.L., C. DÍAZ, C. TOCORNAL y V. ARÉVALO. 2014. Comparando las crónicas y los textos visuales andinos. Elementos para un análisis. Chungara. Revista de Antropología Chilena 46: 91-113.

MOLINA, C. 1916 [1561]. Relación de las fábulas y ritos de los Incas. Colección de libros y documentos referentes a la historia del Perú, Vol. I, pp. 1-103. Sanmarti, Lima.

MULVANY, E. 2004. Motivos de flores en keros coloniales: imágenes y significado. Chungara. Revista de Antropología Chilena 36 (2): 407-419. 
MUÑOZ, I. 1989. El Período Formativo en el Norte Grande (1000 a.C. -500 d.C.). En Culturas de Chile, prehistoria desde sus orígenes hasta los albores de la Conquista, J. Hidalgo, V. Schiappacasse, H. Niemeyer, C. Aldunate, I. Solimano (Eds.), pp. 107-128. Editorial Andrés Bello, Santiago de Chile.

MUÑOZ, I. 2004. Estrategias de organización prehispánicas en Azapa: el impacto de la agricultura en un valle del desierto costero del Pacífico. Ediciones Universidad de Tarapacá, Arica.

NUÑEZ, L. 1963. Los queros del norte de Chile.Antropología 1: 72-88.

OÑA, P. 1944 [1596].Arauco domado, P. Oña (Ed.). Ediciones Cultura Hispánica, Madrid.

ORGAZ, M. 2012. Chicha y aloja. Inkas y autoridades locales en el sector meridional del valle de Yocavil - Catamarca - Argentina. En Surandino Monográfico, segunda sección del Prohal Monográfico, Vol. II, Nro. 2. Buenos Aires.

OWEN, B. y P. GOLDSTEIN. 2001. Tiwanaku en Moquegua: Interacciones Regionales y Colapso. Boletín de Arqueología, Pontificia Universidad Católica del Perú 5: 169-188.

PARDO, O. y J. PIZARRO. 2005. La chicha en el Chile precolombino. Editorial Mare Nostrum, Santiago de Chile.

PEASE, F. 2004. Los últimos incas del cuzco. Instituto Nacional de Cultura del Perú, Lima.

POLO DE ONDEGARDO, J. 1940 [1609]. Informe del Licenciado Juan Polo de Ondegardo al Licenciado Briviesca de Muñatones sobre la perpetuidad de la encomienda en el Perú. Revista Histórica vol.13: 125-196.

POMA DE AYALA, G. 1980 [1615]. Nueva corónica y buen gobierno. J. Murra y R. Adorno (Eds.). Editorial Siglo XXI, México.

RANDALL, R. 1993. Los dos Vasos. Cosmovisión y política de la embriaguez desde el Inkanato hasta la colonia. En Borrachera y Memoria. La experiencia de lo sagrado en los Andes, T. Saignes (Comp.), pp. 103-102. Editorial Hisbol, Instituto Francés de Estudios Andinos (IFEA), La Paz.

RICARDO, A. 2009 [1586]. Arte y vocabulario en la lengua general del Perú llamada quichua y en la lengua española. Agencia Española de Cooperación Internacional para el Desarrollo, Madrid.

ROWE, J.H. 1961. The Chronology of Inka wooden cups. En Essays in pre-columbian art and archaeology, S. Lothtrop y J. Kislak (Eds.), pp. 317-341. Harvard University Press, Cambridge.

ROWE, J.H. 1985. La cronología de los vasos de madera inca. En
Arqueología del Cuzco, pp. 97-136. Instituto Nacional de Cultura Región Cusco, Cusco.

TOLEDO, F. DE. 1882 [1570-72]. Informaciones Acerca del Señorío y Gobierno de los Incas. CLERC 16:35-36.

TORRENCE, R. y H. BARTON. 2006. Ancient Starch Research. Left Coast Press. Walnut Creek, California.

TORRES RUBIO, D. 1754 [1701]. Arte y vocabulario de la lengua quichua general de los indios del Peru. Imprenta de la Plazuela de San Christoval, Lima.

SAIGNES, T. 1993. Borracheras Andinas. ¿Por qué los indios ebrios hablan en español? En Borrachera y Memoria. La experiencia de lo sagrado en los Andes, T. Saignes (Comp.), pp. 43-72. Editorial Hisbol - Instituto Francés de Estudios Andinos (IFEA), La Paz.

SALAZAR-SOLER, C. 1993. Embriaguez y Visiones en los Andes. Los Jesuitas y las "borracheras" indígenas en el Perú (Siglos XVI y XVII). En Borrachera y Memoria. La experiencia de lo sagrado en los Andes, T. Saignes (Comp.), pp. 23-42. Editorial Hisbol - Instituto Francés de Estudios Andinos (IFEA), La Paz.

SANTA CRUZ PACHACUTI YAMQUI SALCAMAYGUA, J. DE. 1993 [ca. 1615]. Relación de antigüedades deste reyno del Pirú, P. Duviols y C. Itier (Eds.). Centro de Estudios regionales Andinos Bartolomé de las Casas ( $\mathrm{CBC}$ ), Instituto Francés de Estudios Andinos (IFEA), Cuzco.

SANTILLÁN, F. DE. 1950 [1563]. Relación del origen, descendencia, política y gobierno de los Incas. En Tres relaciones de antigüedades peruanas. Centro de Estudios Regionales Andinos Bartolomé de las Casas (CBC), Cuzco.

SANTO TOMÁS, D. 1951 [1560]. Lexicon o vocabulario de la lengua general del Perú, por el maestro fray. Instituto de Historia, Universidad Nacional Mayor de San Marcos, Lima.

STEELE, P. 2004. Handbook of Inca mythology. ABC-CLIO, Santa Barbara, California.

VALCÁRCEL, L. 1978. Historia del Antiguo Perú, Tomo III. Editorial Juan Mejía Baca, Lima.

VIVAR, G. DE. 1979 [1558]. Crónica y relación copiosa y verdadera de los Reinos de Chile. Colloquium-Verlag, Berlín.

YOSHIDA, S. 2003. Alcoholic beverages and narcotics in the history of civilization. Senri Ethnological Studies 64: 137-150.

ZIÓLKOWSKI, M. 1979. Acerca de algunas funciones de los keros y los akillas en el Tawantinsuyu Incaico y en el Perú colonial. Estudios Latinoamericanos 5: 11-24. 